\title{
Modified Wisconsin Card Sorting Test (M-WCST): Normative data for the Latin American Spanish speaking adult population
}

J.C. Arango-Lasprilla ${ }^{\mathrm{a}, \mathrm{b}, *}$, D. Rivera ${ }^{\mathrm{b}}$, M. Longonic ${ }^{\mathrm{c}}$, C.P. Saracho ${ }^{\mathrm{d}}$, M.T. Garza ${ }^{\mathrm{e}}$, A. Aliaga ${ }^{\mathrm{f}}$, W. Rodríguez ${ }^{\mathrm{g}}$, Y. Rodríguez-Agudelo ${ }^{\mathrm{h}}$, B. Rábago ${ }^{\mathrm{i}}$, M. Sutter ${ }^{\mathrm{j}}$, S. Schebela ${ }^{\mathrm{k}}$, M. Luna ${ }^{1}$, N. Ocampo-Barba ${ }^{\mathrm{m}}$, J. Galarza-del-Angel ${ }^{\mathrm{n}}$, M.L. Bringas ${ }^{\mathrm{o}}$, L. Esenarro ${ }^{\mathrm{p}}$, C. $_{\text {Martínez }}^{\mathrm{q}}$, P. García-Egan ${ }^{\mathrm{r}}$ and P.B. Perrin ${ }^{\mathrm{j}}$

${ }^{a} I K E R B A S Q U E$, Basque Foundation for Science, Bilbao, Spain

${ }^{\mathrm{b}}$ Faculty of Psychology and Education, University of Deusto, Bilbao, Spain

${ }^{\mathrm{c} C l i ́ n i c a}$ de rehabilitación Las Araucarias, Buenos Aires, Argentina

${ }^{\mathrm{d}}$ CETYS University, Mexicali, Mexico

e Facultad de Psicología Universidad Autónoma de Nuevo León, Monterrey, Mexico

${ }^{\mathrm{f}}$ Servicio Médico Legal, Ministerio de Justicia, Santiago, Chile

${ }^{\mathrm{g}}$ Ponce Health Sciences University, Ponce, Puerto Rico

${ }^{\mathrm{h}}$ Instituto Nacional de Neurología y Neurocirugía MVS, Mexico City, Mexico

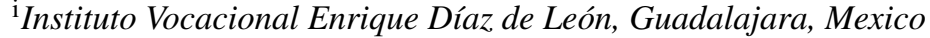

${ }^{\mathrm{j} D e p a r t m e n t ~ o f ~ P s y c h o l o g y, ~ V i r g i n i a ~ C o m m o n w e a l t h ~ U n i v e r s i t y, ~ R i c h m o n d, ~ V A, ~ U S A ~}$

${ }^{\mathrm{k}}$ Instituto de Prevención Social, Asuncion, Paraguay

${ }^{1}$ Universidad Dr. José Matías Delgado, San Salvador, El Salvador

${ }^{\mathrm{m}}$ Fundación Horizontes, Santa Cruz de la Sierra, Bolivia

${ }^{\mathrm{n}}$ Universidad Autónoma de Baja California, Mexicali, Mexico

${ }^{\circ}$ International center for neurological Restoration CIREN, Havana, Cuba

${ }^{\mathrm{p}}$ Instituto de Neuropsicología y Demencias, Lima, Peru

${ }^{\mathrm{q}}$ Departamento de Medicina de Rehabilitación, Nacional Autónoma de Honduras, Tegucigalpa, Honduras

${ }^{\mathrm{r}}$ Departamento de Psicología, Universidad del Valle de Guatemala, Guatemala City, Guatemala

\begin{abstract}
.
OBJECTIVE: To generate normative data on the Modified Card Sorting Test (M-WCST) across 11 countries in Latin America, with country-specific adjustments for gender, age, and education, where appropriate.

METHOD: The sample consisted of 3,977 healthy adults who were recruited from Argentina, Bolivia, Chile, Cuba, El Salvador, Guatemala, Honduras, Mexico, Paraguay, Peru, and Puerto Rico. Each subject was administered the M-WCST as part of a larger neuropsychological battery. A standardized five-step statistical procedure was used to generate the norms.

RESULTS: The final multiple linear regression models explained between 2-33\% of the variance in M-WCST scores. Although $t$-tests showed significant differences between men and women from seven different countries on the M-WCST, the effect sizes were small. As a result, gender-adjusted norms were not generated.

CONCLUSIONS: This is the first normative multicenter study conducted in in Latin America aiming to create norms for the M-WCST; this study will have important implications for the future of neuropsychology in the region.
\end{abstract}

Keywords: Normative data, Modified Wisconsin Card Sorting Test, reference values, Latin America, executive function

*Address for correspondence: Juan Carlos Arango-Lasprilla, Ph.D., IKERBASQUE Research Professor, Department of Psychology, University of Deusto, IKERBASQUE, Basque Foundation for Science, Bilbao, Spain. Tel.: +34 804859 4329; E-mail: jcarango@deusto.es. 


\section{Introduction}

The Modified Wisconsin Card Sorting Test (M-WCST; Nelson, 1976), an adaptation of the Wisconsin Card Sorting Test (WCST; Berg, 1948; Grant $\&$ Berg, 1948), is a widely used neuropsychological test for assessing higher-order cognitive functioning, or executive functioning, that is associated with the frontal lobes of the brain. For successful completion of the M-WCST, the use of abstract reasoning, strategic planning, organized searching, integration of external feedback, mental flexibility, and impulse control are required (Nelson, 1976). Inability to perform such tasks on the M-WCST indicates executive dysfunction.

The original WCST consists of two sets of 64 response cards and four stimulus cards on which the stimulus cards depict a red triangle, two green stars, three yellow crosses, and four blue circles, respectively. The response cards, which have similar patterns but vary in color, geometric shape, and number, are then used to match each card to the four stimuli cards. The individual is given feedback for each turn regarding the correctness of their response. However, the WCST included some ambiguous stimuli that could be classified into more than one category, making the nature of the deficits unclear, and leading to participant frustration (Nelson, 1976; de Zubicaray \& Ashton, 1996).

The M-WCST consists of two sets of 24 response cards, and overcomes the limitations of the WCST by removing the ambiguous stimuli, thus making the test less susceptible to floor effects, especially in older adults and those in rehabilitation settings (Greve, Biachini, Hartley, \& Adams, 1999). Individuals are asked to produce six consecutive successful card sorts to complete a category and are told when the target category is changed, after which they must identify the new rule by sorting the cards properly (Nelson, 1976). The test provides information on aspects of problem solving, such as how many categories are successfully achieved, number of perseverative errors (i.e., failure to utilize negative feedback to change sorting strategy), and number of non-perseverative errors. With these modifications, the M-WCST is considered a completely separate measure from the WCST (de Zubicaray \& Ashton, 1996). Accordingly, only studies utilizing the M-WCST will be summarized.

The M-WCST has been used as a measure of cognitive deficits and frontal lobe functioning in clinical studies with myriad populations. Such studies have evaluated individuals with dementia (Nedjam, Devouche, Dalla Barba, 2004; Traykov et al., 2005);
Alzheimer disease (Bondi, Monsch, Butters, Salmon, \& Paulsen, 1993; Paolo, Axelrod, Troster, Blackwell, \& Koller, 1996); Parkinson's disease (Petrova, Raycheva, Zhelev, \& Traykov, 2010); Huntington's disease (Peinemann et al., 2005; Snowden, Craufurd, Griffiths, Thompson, \& Neary, 2001); temporal and frontal lobe epilepsy (Giovagnoli, 2001); traumatic brain injury (Fork et al., 2005); frontal lobe lesions of various etiologies (Nelson, 1976; Van den Broek, Bradshaw, \& Szabadi, 1993); amnesia of various etiologies (Hunkin, Parkin, \& Longmore, 1994); schizophrenia (Chan et al., 2011); chronic alcoholism (Joyce \& Robbins, 1991); anorexia nervosa (Fassino et al., 2001); and psychopathy (Pham, Vanderstukken, Philippot, \& Vanderlinden, 2003).

Demographic variables such as age, education, sex, and intellectual ability have been significantly associated with performance on the M-WCST. The number and percent of perseverative errors (de Zubicaray, Smith, Chalk, \& Semple, 1998), number of nonperseverative errors, and number of categories achieved (Lineweaver, Bondi, Thomas, \& Salmon, 1999) have been positively associated with age. Additionally, Axelrod \& Henry (1992) demonstrated an increase in perseverative errors after age 60, and Crawford, Bryan, Luszcs, Obonsawin, \& Stewart, (2000) found declined performance in those aged 60 to 75 compared to 18 to 60 year olds. Years of education have been negatively associated with non-perseverative errors (de Zubicaray et al., 1998), perseverative errors (Obonsawin et al., 1999), and positively related to number of categories achieved (de Zubicaray et al., 1998; Lineweaver et al., 1999). However, Plumet, Gil, \& Gaonac'h, (2005) found that education no longer had an effect on distractive errors after age 70, and attentional focus on sorting rules were more affected by age than education. Total number of errors on the M-WCST (Bird, Papadopoulou, Ricciardelli, Rossor, \& Cipolotti, 2004), number of categories completed (Bird et al., 2004; Obonsawin et al., 1999), number and percent of perseverative errors (Obonsawin et al., 1999) have been significantly associated with IQ. Lineweaver et al. (1999) found that sex is associated with non-perseverative errors, such that men make more of these errors than women, but generally there are no sex differences for the M-WCST (Caffarra, Vezzadini, Dieci, Zonato, \& Venneri, 2010; Obonsawin et al., 1999).

Normative data have been accumulated for the M-WCST in various populations. In a review of the M-WCST, de Zubicaray \& Ashton (1996) compiled a summary of healthy control data before any norma- 
tive studies had been conducted. Normative data for healthy English-speaking adults have been obtained by Obonsawin et al. (1999) from 146 individuals between the ages of 16 and 75 years, and by Lineweaver and colleagues (1999) from 229 individuals between the ages of 45 and 91. In Italy, norms have also been developed for adults between the ages of 20 and 90 years (Caffarra et al., 2004), and for children between the ages of 4 and 13 years (Cianchett, Corona, Foscoliano, Contu, \& Sannio-Fancello, 2007). Additionally, normative data for the M-WCST were developed in 465 healthy Chinese individuals between the ages of 16 and 75 (Wang et al., 2011).

To date, there have been no normative data developed for Latin America on the M-WCST despite its wide use in the region. While norms have been developed for Latinos in the United States on the WCST (Rey, Feldman, Rivas-Vazquez, Levin, \& Benton, 1999), none are available for the M-WCST. Because the M-WCST is considered its own measure of executive functioning (de Zubicaray \& Ashton, 1996), scores should not be compared to norms of the WCST. Normative studies on the M-WCST to date have largely ignored the effects of race and ethnicity (e.g., Lineweaver et al., 1999; Obonsawin et al., 1999). It is imperative to develop norms specifically for the Latin American population to accurately assess deficits in executive functioning of the general population, and in the future, elderly and rehabilitation populations in order to identify significant executive dysfunction and implement appropriate treatment interventions.

\section{Method}

\subsection{Participants}

The sample consisted of 3,977 healthy individuals who were recruited from Argentina, Bolivia, Chile, Cuba, El Salvador, Guatemala, Honduras, Mexico, Paraguay, Peru, and, Puerto Rico. The participants were selected according to the following criteria: a) were between 18 to 95 years of age, b) were born and currently lived in the country where the protocol was conducted, c) spoke Spanish as their native language, d) had completed at least one year of formal education, e) were able to read and write at the time of evaluation, f) scored $\geq 23$ on the Mini-Mental State Examination (MMSE, Folstein, Folstein, \& McHugh, 1975), g) scored $\leq 4$ on the Patient Health Questionnaire-9
(PHQ-9, Kroenke, Spitzer, \& Williams, 2001), and h) scored $\geq 90$ on the Barthel Index (Mahoney, \& Barthel, 1965).

Participants with self-reported neurologic or psychiatric disorders were excluded due to a potential effect on cognitive performance. Participants were volunteers from the community and signed an informed consent. Twenty-three participants were excluded from the analyses, with a final sample of 3,954 participants. Socio-demographic and participant characteristics for each of the countries' samples have been reported elsewhere (Guàrdia-Olmos, Peró-Cebollero, Rivera, \& Arango-Lasprilla, 2015). The multi-center study was approved by the Ethics Committee of the coordinating site, the University of Deusto, Spain.

\subsection{Instrument administration}

The M-WCST consists of four stimulus cards and 48 response cards. Each card varies in shape (cross, circle, triangle or star), color (red, blue, yellow or green), and number (one to four). The participant's first response is always considered right, and during the administration, the examiner informs whether the choice is correct or not until the subject correctly classifies six consecutive cards to complete a category. Then, the examiner indicates that the rules have changed and to try to "find another rule." If the second category chosen differs from that which was chosen in the first is considered correct. The test continues until all six categories are classified or until the whole volume has been used (Schretlen, 2010; Greve, 2001; Nelson, 1976). The test allows for calculation of the number of categories, perseverations, and total errors.

\subsection{Statistical analyses}

The detailed statistical analyses used to generate the normative data for this test are described in Guàrdia-Olmos, et al. (2015). In summary, the data manipulation process for each country-specific dataset involved five-steps: a) $t$ - tests for independent samples and effect sizes $(r)$ were conducted to determine gender effects. If the effect size was larger than 0.3, gender was included in the model with gender dummy coded and female as the reference group (male $=1$ and female $=0$ ). b) A multivariable regression model was used to specify the predictive model including gender (if effect size was larger than 0.3), age as a continuous variable, and education as a dummy coded variable with 1 if the participant had $>12$ years of education 
Table 1

Effect of gender in the M-WCST numbers of categories

\begin{tabular}{|c|c|c|c|c|c|c|}
\hline Country & Gender & Mean (SD) & $t$ & $\mathrm{df}$ & Sig. (2-tailed) & $r$ \\
\hline \multirow[t]{2}{*}{ Argentina $^{a}$} & Male & $5.8(0.5)$ & 2.62 & 306.4 & $0.009^{* *}$ & 0.148 \\
\hline & Female & $5.6(1.0)$ & & & & \\
\hline \multirow[t]{2}{*}{ Bolivia } & Male & $4.4(1.8)$ & 0.23 & 272 & 0.815 & 0.014 \\
\hline & Female & $4.4(1.7)$ & & & & \\
\hline \multirow[t]{2}{*}{ Chile $^{\mathrm{a}}$} & Male & $5.5(1.1)$ & 2.44 & 317.5 & $0.015^{*}$ & 0.136 \\
\hline & Female & $5.1(1.4)$ & & & & \\
\hline \multirow[t]{2}{*}{ Cuba } & Male & $4.7(1.5)$ & 0.84 & 304 & 0.400 & 0.048 \\
\hline & Female & $4.6(1.6)$ & & & & \\
\hline \multirow[t]{2}{*}{ El Salvador } & Male & $4.1(2.1)$ & 2.39 & 255 & $0.018^{*}$ & 0.148 \\
\hline & Female & $3.4(2.1)$ & & & & \\
\hline \multirow[t]{2}{*}{ Guatemala $^{a}$} & Male & $4.1(2.0)$ & -2.50 & 181.7 & $0.013^{*}$ & 0.182 \\
\hline & Female & $4.7(1.7)$ & & & & \\
\hline \multirow[t]{2}{*}{ Honduras } & Male & $3.9(1.9)$ & 2.66 & 182 & $0.008^{* *}$ & 0.194 \\
\hline & Female & $3.1(2.1)$ & & & & \\
\hline \multirow[t]{2}{*}{ Mexico $^{\mathrm{a}}$} & Male & $4.8(1.6)$ & 3.54 & 910.5 & $<0.001^{* * *}$ & 0.116 \\
\hline & Female & $4.5(1.8)$ & & & & \\
\hline \multirow[t]{2}{*}{ Paraguay } & Male & $5.1(0.9)$ & 2.94 & 261 & $0.004^{* *}$ & 0.179 \\
\hline & Female & $4.8(0.9)$ & & & & \\
\hline \multirow[t]{2}{*}{ Peru } & Male & $4.3(1.7)$ & -1.60 & 241 & 0.112 & 0.102 \\
\hline & Female & $4.7(1.6)$ & & & & \\
\hline \multirow[t]{2}{*}{ Puerto Rico } & Male & $5.2(1.4)$ & 0.69 & 288 & 0.493 & 0.040 \\
\hline & Female & $5.1(1.6)$ & & & & \\
\hline
\end{tabular}

${ }^{a}$ Value of the $t$-test for independent groups from the different variances with the corresponding correction of Yuen-Welch of degrees of freedom. ${ }^{*} p<0.05,{ }^{* *} p<0.01,{ }^{* * *} p<0.001$.

and 0 if participants had $1-12$ years of education. If gender, age and/or education were not statistically significant in this multivariate model with an alpha of 0.05 , the non-significant variables were removed and the model was re-run. Then a final regression model was conducted that included age (if statistically significant in the multivariate model), dichotomized education (if statistically significant in the multivariate model), and/or gender (if effect size was greater than 0.3) $\quad\left[\widehat{y}_{i}=\beta_{0}+\left(\beta_{\text {Age }} \cdot A g e_{i}\right)+\left(\beta_{E d u c} \cdot E d u c_{i}\right)+\right.$ $\left(\beta_{\text {Gender }} \cdot\right.$ Gender $\left.\left.\left._{i}\right)\right] ; \mathrm{c}\right)$ residual scores were calculated based on this final model $\left.\left(e_{i}=y_{i}-\widehat{y}_{i}\right) ; \mathrm{d}\right)$ using the $\mathrm{SD}$ (residual) value provided by the regression model, residuals were standardized: $z=e_{i} / S D_{e}$, with $S D_{e}$ (residual) $=$ the standard deviation of the residuals in the normative sample; and e) standardized residuals were converted to percentile values (Strauss et al., 2006). Using each country's dataset, these steps were applied to M-WCST number of categories correct, perseverative errors, and total errors.

\section{Results}

\subsection{Number of categories correct}

Regarding the effect of gender on M-WCST numbers of categories correct, the $t$-tests showed significant differences between men and women for Argentina,
Chile, El Salvador, Guatemala, Honduras, Mexico, and Paraguay, however, none of these four countries had an effect size larger than 0.3 . Table 1 shows the results of the gender analyses by country on M-WCST numbers of correct categories. As shown in Table 1, the effect sizes for all countries were less than 0.3 , and therefore gender was not taken into account to generate the normative data for M-WCST number of correct categories scores for any of the countries in the study.

The final eleven M-WCST numbers of correct categories multivariate linear regression models for each country are shown in Table 2 . In all countries, except Bolivia, and Chile, the M-WCST numbers of correct categories increased for those with more than 12 years of education (see Table 2), and, in all countries except Guatemala, M-WSCT number of correct categories decreased in a linear fashion as a function of age. The amount of variance explained in M-WCST numbers of correct categories ranged from $7 \%$ (in Argentina) to $33 \%$ (in Peru).

\subsection{Number of perseverative errors}

Regarding the effect of gender on M-WCST number of perseverative errors, the $t$-tests showed significant differences between men and women in the countries of Chile, Guatemala, Honduras, Mexico, Paraguay, and 
Table 2

Final multiple linear regression models for M-WCST categories scores

\begin{tabular}{|c|c|c|c|c|c|c|c|}
\hline Country & & $\mathrm{B}$ & Std. Error & $t$ & Sig. & $\mathrm{R}^{2}$ & $S D_{e}$ (residual) \\
\hline \multirow[t]{3}{*}{ Argentina } & (Constant) & 5.753 & 0.135 & 42.597 & $<0.001$ & 0.067 & 0.828 \\
\hline & Age & -0.006 & 0.002 & -2.459 & 0.014 & & \\
\hline & Education & 0.352 & 0.094 & 3.741 & $<0.001$ & & \\
\hline \multirow[t]{2}{*}{ Bolivia } & (Constant) & 5.793 & 0.274 & 21.163 & $<0.001$ & 0.099 & 1.656 \\
\hline & Age & -0.025 & 0.005 & -5.465 & $<0.001$ & & \\
\hline \multirow[t]{2}{*}{ Chile } & (Constant) & 6.229 & 0.207 & 30.077 & $<0.001$ & 0.072 & 1.238 \\
\hline & Age & -0.018 & 0.004 & -4.969 & $<0.001$ & & \\
\hline \multirow[t]{3}{*}{ Cuba } & (Constant) & 5.785 & 0.240 & 24.071 & $<0.001$ & 0.134 & 1.415 \\
\hline & Age & -0.024 & 0.004 & -5.834 & $<0.001$ & & \\
\hline & Education & 0.616 & 0.192 & 3.210 & 0.001 & & \\
\hline \multirow[t]{2}{*}{ Guatemala } & (Constant) & 3.924 & 0.149 & 26.273 & $<0.001$ & 0.142 & 1.705 \\
\hline & Education & 1.422 & 0.242 & 5.886 & $<0.001$ & & \\
\hline \multirow[t]{3}{*}{ El Salvador } & (Constant) & 4.269 & 0.357 & 11.970 & $<0.001$ & 0.194 & 1.916 \\
\hline & Age & -0.018 & 0.006 & -3.113 & 0.002 & & \\
\hline & Education & 2.047 & 0.295 & 6.935 & $<0.001$ & & \\
\hline \multirow[t]{3}{*}{ Honduras } & (Constant) & 4.950 & 0.401 & 12.330 & $<0.001$ & 0.214 & 1.808 \\
\hline & Age & -0.038 & 0.007 & -5.201 & $<0.001$ & & \\
\hline & Education & 1.129 & 0.321 & 3.513 & 0.001 & & \\
\hline \multirow[t]{3}{*}{ Mexico } & (Constant) & 5.792 & 0.133 & 43.577 & $<0.001$ & 0.129 & 1.628 \\
\hline & Age & -0.026 & 0.002 & -11.461 & $<0.001$ & & \\
\hline & Education & 0.658 & 0.111 & 5.935 & $<0.001$ & & \\
\hline \multirow[t]{3}{*}{ Paraguay } & (Constant) & 5.754 & 0.216 & 26.607 & $<0.001$ & 0.186 & 0.819 \\
\hline & Age & -0.017 & 0.004 & -4.583 & $<0.001$ & & \\
\hline & Education & 0.555 & 0.145 & 3.837 & $<0.001$ & & \\
\hline \multirow[t]{3}{*}{ Peru } & (Constant) & 5.256 & 0.257 & 20.482 & $<0.001$ & 0.328 & 1.358 \\
\hline & Age & -0.033 & 0.004 & -7.589 & $<0.001$ & & \\
\hline & Education & 1.143 & 0.186 & 6.155 & $<0.001$ & & \\
\hline \multirow[t]{3}{*}{ Puerto Rico } & (Constant) & 6.369 & 0.278 & 22.911 & $<0.001$ & 0.161 & 1.388 \\
\hline & Age & -0.029 & 0.005 & -6.156 & $<0.001$ & & \\
\hline & Education & 0.412 & 0.170 & 2.428 & 0.016 & & \\
\hline
\end{tabular}

Peru. Table 3 shows the results of the gender analysis by country on M-WCST number of perseverative errors. As shown in Table 3, the effect sizes for all countries were less than 0.3 , and therefore gender was not taken into account to generate M-WCST number of perseverative errors normative data.

The final eleven multivariate linear regression models for the M-WCST number of perseverative errors for each country are shown in Table 4. In all countries, except Bolivia and Chile, the M-WCST number of perseverative errors decreased for those with more than 12 years of education (see Table 4) and, except Honduras and Guatemala, M-WCST number of perseverative errors increased in a linear fashion as a function of age. The amount of variance explained in M-WCST number of perseverative errors ranged from $3 \%$ (in Chile) to $32 \%$ (in Paraguay).

\subsection{Number of total errors}

Regarding the effect of gender on M-WCST number of total errors, the $t$-tests showed significant differ- ences between men and women for Chile, Mexico, and Paraguay. Table 5 shows the results of the gender analysis by country on M-WCST number of total errors. As shown in Table 5, the effect sizes for all countries were less than 0.3 , and therefore gender was not taken into account to generate M-WCST number of total errors normative data.

The final eleven multivariate linear regression models for the M-WCST number of total errors for each country are shown in Table 6 . In all countries, except Bolivia and Chile, the M-WCST number of total errors decreased for those with more than 12 years of education (see Table 6) and, except Guatemala and Honduras, increased in a linear fashion as a function of age. The amount of variance explained in M-WCST number of total errors ranged from $2 \%$ (in Chile) to $33 \%$ (in Paraguay).

\section{Normative procedure}

Norms (e.g., a percentile score) for the M-WCST different scores were established using the five-step 
Table 3

Effect of gender in the M-WCST Perseveration errors

\begin{tabular}{|c|c|c|c|c|c|c|}
\hline Country & Gender & Mean (SD) & $t$ & df & Sig. (2-tailed) & $r$ \\
\hline \multirow[t]{2}{*}{ Argentina $^{\mathrm{a}}$} & Male & $3.7(2.6)$ & 0.08 & 306.7 & 0.934 & 0.005 \\
\hline & Female & $3.7(5.0)$ & & & & \\
\hline \multirow[t]{2}{*}{ Bolivia } & Male & $7.1(7.7)$ & 0.25 & 272 & 0.801 & 0.015 \\
\hline & Female & $6.9(6.8)$ & & & & \\
\hline \multirow[t]{2}{*}{ Chile $^{\mathrm{a}}$} & Male & $1.7(3.2)$ & -3.05 & 308.4 & $0.003^{* *}$ & 0.171 \\
\hline & Female & $3.1(5.3)$ & & & & \\
\hline \multirow[t]{2}{*}{ Cuba } & Male & $4.6(6.0)$ & -1.51 & 303 & 0.132 & 0.086 \\
\hline & Female & $5.8(7.3)$ & & & & \\
\hline \multirow[t]{2}{*}{ El Salvador } & Male & $6.5(6.7)$ & -1.19 & 255 & 0.236 & 0.074 \\
\hline & Female & $7.5(6.3)$ & & & & \\
\hline \multirow[t]{2}{*}{ Guatemala $^{\mathrm{a}}$} & Male & $7.0(9.0)$ & 2.28 & 150.6 & $0.024^{*}$ & 0.183 \\
\hline & Female & $4.5(5.9)$ & & & & \\
\hline \multirow[t]{2}{*}{ Honduras } & Male & $5.6(4.7)$ & -2.47 & 182 & $0.014^{*}$ & 0.180 \\
\hline & Female & $8.0(7.0)$ & & & & \\
\hline \multirow[t]{2}{*}{ Mexico $^{\mathrm{a}}$} & Male & $4.1(5.8)$ & -3.21 & $1,004.4$ & $0.001^{* * *}$ & 0.101 \\
\hline & Female & $5.3(7.1)$ & & & & \\
\hline \multirow[t]{2}{*}{ Paraguay } & Male & $5.5(3.0)$ & -3.78 & 261 & $<0.001^{* * *}$ & 0.228 \\
\hline & Female & $6.9(2.8)$ & & & & \\
\hline \multirow[t]{2}{*}{ Peru $^{a}$} & Male & $5.1(6.5)$ & 2.27 & 118.6 & $0.025^{*}$ & 0.204 \\
\hline & Female & $3.4(3.8)$ & & & & \\
\hline \multirow[t]{2}{*}{ Puerto Rico } & Male & $3.5(6.9)$ & 0.29 & 288 & 0.772 & 0.017 \\
\hline & Female & $3.7(7.1)$ & & & & \\
\hline
\end{tabular}

a Value of the $t$-test for independent groups from the different variances with the corresponding correction of Yuen-Welch of degrees of freedom. ${ }^{*} p<0.05,{ }^{* *} p<0.01,{ }^{* * *} p<0.001$.

Table 4

Final multiple linear regression models for M-WCST Perseveration errors

\begin{tabular}{|c|c|c|c|c|c|c|c|}
\hline Country & & $\mathrm{B}$ & Std. Error & $t$ & Sig. & $\mathrm{R}^{2}$ & $S D_{e}$ (residual) \\
\hline \multirow[t]{3}{*}{ Argentina } & (Constant) & 3.384 & 0.684 & 4.945 & $<0.001$ & 0.113 & 4.196 \\
\hline & Age & 0.036 & 0.012 & 2.943 & 0.003 & & \\
\hline & Education & -2.468 & 0.476 & -5.183 & $<0.001$ & & \\
\hline \multirow[t]{2}{*}{ Bolivia } & (Constant) & 0.970 & 1.114 & 0.870 & 0.385 & 0.110 & 6.744 \\
\hline & Age & 0.108 & 0.019 & 5.813 & $<0.001$ & & \\
\hline \multirow[t]{2}{*}{ Chile } & (Constant) & 0.453 & 0.760 & 0.596 & 0.552 & 0.025 & 4.546 \\
\hline & Age & 0.037 & 0.013 & 2.884 & 0.004 & & \\
\hline \multirow[t]{3}{*}{ Cuba } & (Constant) & 1.748 & 1.107 & 1.579 & 0.115 & 0.070 & 6.508 \\
\hline & Age & 0.075 & 0.019 & 3.972 & 0.001 & & \\
\hline & Education & -2.069 & 0.882 & -2.345 & 0.020 & & \\
\hline \multirow[t]{3}{*}{ El Salvador } & (Constant) & 4.663 & 1.111 & 4.197 & $<0.001$ & 0.149 & 5.969 \\
\hline & Age & 0.062 & 0.018 & 3.413 & 0.001 & & \\
\hline & Education & -5.031 & 0.920 & -5.470 & $<0.001$ & & \\
\hline \multirow[t]{2}{*}{ Guatemala } & (Constant) & 6.847 & 0.644 & 10.625 & $<0.001$ & 0.044 & 7.358 \\
\hline & Education & -3.255 & 1.043 & -3.122 & 0.002 & & \\
\hline \multirow[t]{2}{*}{ Honduras } & (Constant) & 7.750 & 0.530 & 14.621 & $<0.001$ & 0.030 & 6.254 \\
\hline & Education & -2.568 & 1.084 & -2.369 & 0.019 & & \\
\hline \multirow[t]{3}{*}{ Mexico } & (Constant) & -0.092 & 0.513 & -0.180 & 0.857 & 0.125 & 6.282 \\
\hline & Age & 0.103 & 0.009 & 11.874 & $<0.001$ & & \\
\hline & Education & -2.048 & 0.428 & -4.785 & $<0.001$ & & \\
\hline \multirow[t]{3}{*}{ Paraguay } & (Constant) & 3.351 & 0.651 & 5.143 & $<0.001$ & 0.320 & 2.469 \\
\hline & Age & 0.066 & 0.011 & 5.888 & $<0.001$ & & \\
\hline & Education & -2.707 & 0.436 & -6.216 & $<0.001$ & & \\
\hline \multirow[t]{3}{*}{ Peru } & (Constant) & 1.339 & 0.823 & 1.628 & 0.105 & 0.241 & 4.352 \\
\hline & Age & 0.096 & 0.014 & 6.910 & $<0.001$ & & \\
\hline & Education & -2.351 & 0.595 & -3.949 & $<0.001$ & & \\
\hline \multirow[t]{3}{*}{ Puerto Rico } & (Constant) & -0.139 & 1.325 & -0.105 & 0.916 & 0.108 & 6.614 \\
\hline & Age & 0.095 & 0.022 & 4.310 & $<0.001$ & & \\
\hline & Education & -2.252 & 0.808 & -2.787 & 0.006 & & \\
\hline
\end{tabular}


Table 5

Effect of gender in the M-WCST total errors

\begin{tabular}{|c|c|c|c|c|c|c|}
\hline Country & Gender & Mean (SD) & $t$ & $\mathrm{df}$ & Sig. (2-tailed) & $r$ \\
\hline \multirow[t]{2}{*}{ Argentina $^{a}$} & Male & $6.8(4.4)$ & -0.30 & 263.48 & 0.762 & 0.019 \\
\hline & Female & $7.0(6.7)$ & & & & \\
\hline \multirow[t]{2}{*}{ Bolivia } & Male & $14.5(11.2)$ & 0.04 & 272 & 0.966 & 0.003 \\
\hline & Female & $14.4(11.1)$ & & & & \\
\hline \multirow[t]{2}{*}{ Chile $^{\mathrm{a}}$} & Male & $6.0(6.5)$ & -3.31 & 317.88 & $0.001^{* *}$ & 0.182 \\
\hline & Female & $8.9(9.2)$ & & & & \\
\hline \multirow[t]{2}{*}{ Cuba } & Male & $12.0(9.6)$ & -0.93 & 304 & 0.354 & 0.053 \\
\hline & Female & $13.0(9.8)$ & & & & \\
\hline \multirow[t]{2}{*}{ El Salvador } & Male & $15.1(11.8)$ & -1.94 & 255 & 0.054 & 0.120 \\
\hline & Female & $17.9(10.9)$ & & & & \\
\hline \multirow[t]{2}{*}{ Guatemala $^{\mathrm{a}}$} & Male & $13.9(11.7)$ & 2.24 & 174.3 & $0.03^{*}$ & 0.167 \\
\hline & Female & $10.5(9.4)$ & & & & \\
\hline \multirow[t]{2}{*}{ Honduras } & Male & $14.2(8.7)$ & -1.15 & 182 & 0.252 & 0.085 \\
\hline & Female & $15.9(10.2)$ & & & & \\
\hline \multirow[t]{2}{*}{ Mexico $^{a}$} & Male & $10.8(10.4)$ & -3.73 & 924.42 & $<0.001^{* * *}$ & 0.122 \\
\hline & Female & $13.2(11.4)$ & & & & \\
\hline \multirow[t]{2}{*}{ Paraguay } & Male & $11.0(6.0)$ & -4.06 & 261 & $<0.001^{* * *}$ & 0.244 \\
\hline & Female & $14.0(5.6)$ & & & & \\
\hline \multirow[t]{2}{*}{ Peru } & Male & $13.4(10.0)$ & 1.82 & 241 & 0.070 & 0.116 \\
\hline & Female & $11.1(9.3)$ & & & & \\
\hline \multirow[t]{2}{*}{ Puerto Rico } & Male & $9.2(9.8)$ & -0.46 & 288 & 0.647 & 0.027 \\
\hline & Female & $9.7(10.2)$ & & & & \\
\hline
\end{tabular}

${ }^{a}$ Value of the $t$-test for independent groups from the different variances with the corresponding correction of Yuen-Welch of degrees of freedom. ${ }^{*} p<0.05,{ }^{* *} p<0.01,{ }^{* * *} p<0.001$.

procedure described above. To facilitate the understanding of the procedure to obtain the percentile associated with a score on this test, an example will be given. Suppose you need to find the percentile score for a Mexican man, who is 50 years old and has 15 years of education. He has completed four categories on the M-WCST. The steps to obtain the percentile for this score are: a) Check Table 1 to determine if the effect size of gender in the country of interest (Mexico) on this test and task (MWCST numbers of categories corrects) is greater than 0.3 by country. The column labelled $r$ in Table 1 indicates the effect size. In this example, the effect size is 0.116 , which is not greater than 0.3. For Mexicans on this test, gender does not influence scores to a sufficient degree to take it into account when determining the percentile. b) Find Mexico in Table 2, which provides the final regression models by country for M-WCST numbers of correct categories. Use the B weights to create an equation that will allow you to obtain the predicted M-WCST numbers of correct categories. The corresponding $\mathrm{B}$ weights are multiplied by the actual age and dichotomized education scores and added to a constant in order to calculate the predicted value. In this case, the predicted M-WCST numbers of categories corrects would be calculated using the equation $\left[\widehat{y}_{i}=5.792+\left(-0.026 \cdot\right.\right.$ Age $\left._{i}\right)+(0.658$. Dichotomized Educational Level $)_{i}$ )] (the values have been rounded for presentation in the formula). The sub- script notation $i$ indicate the person of interest. The person's age is 50 , but the education variable is not continuous in the model. Years of education is split into either 1 to 12 years (and assigned a 0 ) or more than 12 years (and assigned a 1) in the model. Since our hypothetical person in the example has 15 years of education, his educational level value is 1 . Thus the predicted value is $5.792+(-0.026 \cdot 50)+(0.658 \cdot 1)=$ $5.792+(-1.292)+0.658=5.159)$. c). In order to calculate the residual value (indicated with an e in the equation), we subtract the actual value from the predicted value we just calculated $\left(e_{i}=y_{i}-\widehat{y_{i}}\right)$. In this case, it would be $e_{i}=4-5.159=-1.159$. d) Next, consult the $S D_{e}$ column in Table 2 to obtain the countryspecific $S D_{e}$ (residual) value. For Mexico it is 1.628. Using this value, we can transform the residual value to a standardized $z$ score using the equation $\left(e_{i} / S D_{e}\right)$. In this case, we have $(-1.159) / 1.628=-0.712$. This is the standardized $z$ score for a Mexican man aged 50 and 15 years of education and four categories completed in the M-WCST. e) The last step is to look-up the tables in the statistical reference books (e.g. Strauss et al., 2006) or use a trusted online calculator like the one available at http://www.measuringu.com/pcalcz.php. In the online calculator, you would enter the $z$ score and choose a one-sided test and note the percent of area after hitting the submit button. In this case, the probability of -0.712 corresponds to the 23 th percentile. Please remember to 
use the appropriate tables that correspond to each test when performing these calculations. If the percentile for the others M-WCST scores is desired, Tables 3-6 must be used.

\subsection{User-friendly normative data}

The five-step normative procedures explained above can provide more individualized norms. However, this method can be prone to human error due to the number of required computations. To enhance user-friendliness, the authors have completed these steps for a range of raw scores based on small age range groupings (see Guàrdia-Olmos, et al., 2015) and created tables that clinicians can more easily use to obtain a percentile range associated with a given raw score on this test. These tables are available by country and type of test in the Appendix. In order to obtain an approximate percentile for the above example (converting a raw score of four categories for a Mexican man who is 50 years old and has 15 years of education) using the simplified normative tables provided, the following steps are recommended. (1) First, identify the appropriate table ensuring the specific country and test. In this case, the table for M-WCST numbers of categories corrects for Mexico can be found in Table A8. (2) Note if the title of the table indicates that it is only to be used for one specific gender. In this case, gender is not specified. Thus Table A8 is used for both males and females. (3) Next, the table is divided based on educational level ( 1 to 12 vs. more than 12 years of education). Since this man has 15 years of education, he falls into the more than 12 years of education category. These data can be found in the top section of the table. (4) Determine the age range most appropriate for the individual. In this case, 50 falls into the column 48-52 years of age. (5) Read down the age range column to find the approximate location of the raw score the person obtained on the test. Reading down the 48-52 column, the score of four obtained by this Mexican man corresponds to an approximate percentile of 20 .

The percentile obtained via this user-friendly table method (20th) is slightly different from the more exact one (23th) obtained following the individual conversion steps above because the table method is based on an age range (e.g., individuals aged 48-52) instead of the exact age (individuals aged 50). If the exact score is not listed in the column, you must estimate the percentile value from the listed raw scores.

\section{Discussion}

The purpose of the current study was to generate normative data on the M-WCST across 11 countries in Latin America, with country-specific adjustments for gender, age, and education, where appropriate. The final multiple linear regression models explained between $7-33 \%$ of the variance in M-WCST number of categories correct, $3-32 \%$ of the variance in number of perseverative errors, and $2-33 \%$ of the variance in number of total errors. Although there were a number of gender differences across various M-WCST scores in different countries, all effect sizes were small, and therefore gender-adjusted norms were not generated for any country. These findings tend to concur with the previous literature. Although one study found men to make more perseverative errors than women (Lineweaver et al., 1999), most studies have found no gender differences in performance on the M-WCST (Caffarra et al., 2010; Obonsawin et al., 1999). In light of the previous literature, the results from the current study suggest that gender should not be taken into account in calculating percentiles for the M-WCST in Latin America.

The various M-WCST scores generally increased linearly as a function of education in most countries. However, this was not true for number of categories correct, number of perseverative errors, or number of total errors in Chile and Bolivia. This general pattern of findings corroborated previous research which has found higher education to be negatively associated with non-perseverative errors (de Zubicaray et al., 1998) and perseverative errors (Obonsawin et al., 1999), as well as positively associated with number of categories correct (de Zubicaray et al., 1998; Lineweaver et al., 1999). When considering this previous research, it is suggested that neuropsychologists in Latin America use the education-adjusted norms generated for each country when administering the M-WCST in that country, except in Chile and Bolivia on the various M-WCST score categories which showed no effect of education. Because there are likely large differences in the quality of education throughout different countries in Latin America, the current data's education adjustments will be useful when administering the M-WCST across many different Latin American countries.

M-WCST scores worsened with increasing age in all countries except for on the number of perseverative errors and number of total errors in Honduras and Guatemala. Previous studies have found that higher age is associated with a greater number and percent of perseverative errors (Axelrod \& Henry, 1992; de Zubicaray 
Table 6

Final multiple linear regression models for M-WCST total errors

\begin{tabular}{|c|c|c|c|c|c|c|c|}
\hline Country & & $\mathrm{B}$ & Std. Error & $t$ & Sig. & $\mathrm{R}^{2}$ & $S D_{e}$ (residual) \\
\hline \multirow[t]{3}{*}{ Argentina } & (Constant) & 6.676 & 0.918 & 7.269 & $<0.001$ & 0.149 & 5.631 \\
\hline & Age & 0.052 & 0.016 & 3.189 & 0.002 & & \\
\hline & Education & -3.999 & 0.639 & -6.257 & $<0.001$ & & \\
\hline \multirow[t]{2}{*}{ Bolivia } & (Constant) & 0.970 & 1.114 & 0.870 & 0.385 & 0.110 & 6.744 \\
\hline & Age & 0.108 & 0.019 & 5.813 & $<0.001$ & & \\
\hline \multirow[t]{2}{*}{ Chile } & (Constant) & 0.453 & 0.760 & 0.596 & 0.552 & 0.025 & 4.546 \\
\hline & Age & 0.037 & 0.013 & 2.884 & 0.004 & & \\
\hline \multirow[t]{3}{*}{ Cuba } & (Constant) & 6.351 & 1.567 & 4.053 & $<0.001$ & 0.103 & 9.225 \\
\hline & Age & 0.132 & 0.027 & 4.919 & $<0.001$ & & \\
\hline & Education & -3.626 & 1.250 & -2.901 & 0.004 & & \\
\hline \multirow[t]{3}{*}{ El Salvador } & (Constant) & 13.621 & 1.875 & 7.264 & $<0.001$ & 0.212 & 10.073 \\
\hline & Age & 0.100 & 0.031 & 3.255 & 0.001 & & \\
\hline & Education & -11.424 & 1.552 & -7.360 & 0.001 & & \\
\hline \multirow[t]{2}{*}{ Guatemala } & (Constant) & 14.863 & 0.871 & 17.054 & $<0.001$ & 0.119 & 9.951 \\
\hline & Education & -7.505 & 1.410 & -5.323 & $<0.001$ & & \\
\hline \multirow[t]{2}{*}{ Honduras } & (Constant) & 7.750 & 0.530 & 14.621 & $<0.001$ & 0.030 & 6.254 \\
\hline & Education & -2.568 & 1.084 & -2.369 & 0.019 & & \\
\hline \multirow[t]{3}{*}{ Mexico } & (Constant) & 3.675 & 0.842 & 4.365 & $<0.001$ & 0.146 & 10.312 \\
\hline & Age & 0.182 & 0.014 & 12.740 & $<0.001$ & & \\
\hline & Education & -4.018 & 0.702 & -5.721 & $<0.001$ & & \\
\hline \multirow[t]{3}{*}{ Paraguay } & (Constant) & 4.670 & 1.282 & 3.644 & $<0.001$ & 0.330 & 4.856 \\
\hline & Age & 0.167 & 0.022 & 7.537 & $<0.001$ & & \\
\hline & Education & -4.024 & 0.857 & -4.697 & $<0.001$ & & \\
\hline \multirow[t]{3}{*}{ Peru } & (Constant) & 6.362 & 1.563 & 4.069 & $<0.001$ & 0.260 & 8.271 \\
\hline & Age & 0.195 & 0.026 & 7.375 & $<0.001$ & & \\
\hline & Education & -4.496 & 1.132 & -3.973 & $<0.001$ & & \\
\hline \multirow[t]{3}{*}{ Puerto Rico } & (Constant) & 1.283 & 1.831 & 0.701 & 0.484 & 0.166 & 9.144 \\
\hline & Age & 0.189 & 0.031 & 6.183 & 0.001 & & \\
\hline & Education & -2.940 & 1.117 & -2.632 & 0.009 & & \\
\hline
\end{tabular}

et al., 1998) and number of non-perseverative errors, as well as inversely with number of categories correct (Lineweaver et al., 1999). When considering the previous findings, those from the current study suggest that M-WCST corrections for age in Latin America should be made in all countries except in Honduras and Guatemala on the M-WCST score categories that showed no age effect.

\subsection{Limitations and future directions}

This study has several limitations and perhaps as a result, directions for future research. First, all participants in this study spoke Spanish as a primary language, but data were not collected on bilingualism. Because M-WCST performance could potentially differ for people who speak secondary languages, future research would benefit from examining effects of bilingualism on performance. Data collection occurred in specific cities or regions of the countries in Latin America instead of nationally. The current study is the largest neuropsychological normative study conducted to date in Latin America for the M-WCST, or in any global region, and thus it should be seen as a first step for larger and nationally representative normative studies. The sample was limited in that although many participants had fewer than 12 years of education, illiterate individuals were ineligible to participate and the current norms may not generalize to illiterate adults. In the same manner, participants with a history of neurological conditions and children were not sampled, so future studies should be conducted with these populations.

Second, neuropsychologists should be careful about using the M-WCST norms generated in this study for people in countries other than those from which data were collected. Future studies need to create M-WCST norms in other countries in Latin America including Ecuador, Uruguay, Venezuela, and Panama. Despite this limitation, the current M-WCST norms may be more accurate in Latin American countries not a part of this study than other norms currently in use. This generalizability is a critical area for future research.

Third, the M-WCST is a common instrument in Latin America, but other instruments should be normed following similar procedures in order to improve their use 
in this region. Future studies should similarly examine the psychometric properties and ecological validity of the M-WCST, as well as other common assessment tools in Latin America. Researchers should also create instruments within Latin American cultures with good ecological validity, because the M-WCST was created in a Western culture different from the various cultures in Latin America. Future studies should create assessments within local cultures, not just translate and norm tests from other countries.

Despite these limitations, no studies have yet produced M-WCST norms in Spanish-speaking populations. This study was the first to generate M-WCST norms across 11 countries in Latin America with nearly 4,000 participants. It was the largest, most comprehensive M-WCST normative study to date in any global region, and its norms will likely affect the standard of neuropsychological assessment with the M-WCST in Latin America unlike any study before it.

\section{References}

Axelrod, B. N., \& Henry R. R. (1992). Age-related performance on the Wisconsin card sorting, similarities, and controlled oral word association tests. Clinical Neuropsychologist, 6(1), 16-26.

Berg, E. A. (1948). A simple objective technique for measuring flexibility in thinking. Journal of General Psychology, 39(1), 15-22.

Bird, C. M., Papadopoulou, K., Ricciardelli, P., Rossor, M. N., \& Cipolotti, L. (2004). Monitoring cognitive changes: Psychometric properties of six cognitive tests. British Journal of Clinical Psychology, 43(2), 197-210.

Bondi, M. W., Monsch, A. U., Butters, N., Salmon, D. P.,\& Paulsen, J. (1993). Utility of a modified version of the Wisconsin Card Sorting Test in the detection of dementia of the Alzheimer type. The Clinical Neuropsychologist, 7(2), 161-170.

Caffarra, P., Vezzadini, G., Dieci, F., Zonato, F., \& Venneri, A. (2010) Modified card sorting test: Normative data. Journal of Clinical and Experimental Neuropsychology, 26(2), 246-250.

Chan, S. K. W., Chan, K. K. S., Lam, M. M. L., Chiu, C. P. Y., Hui, C. L. M., Wong, G. H. Y., \& Chen, E. Y. H. (2011). Clinical and cognitive correlates of insight in first-episode schizophrenia. Schizophrenia Research, 135(1), 40-45.

Cianchett, C., Corona, S., Foscoliano, M., Contu, D., \& SannioFancello, G. (2007) Modified Wisconsin Card Sorting Test (M-WCST, MWCST): Normative data in children 4-13 years old, according to classical and new types of scoring. The Clinical Neuropsychologist, 21(3), 456-578.

Crawford, J., Bryan, J., Luszcz, M., Obonsawin, M., \& Stewart, L. (2000). The executive decline hypothesis of cognitive aging: Do executive deficits qualify as differential deficit and do they mediate age-related memory decline? Aging, Neuropsychology and Cognition, 7(1), 9-31.

de Zubicaray, G. \& Ashton, R. (1996). Nelson's (1976) Modified Card Sorting Test: A review. The Clinical Neuropsychologist, 10(3), 245-254. de Zubicaray, G. I., Smith, G. A., Chalk, J. B., \& Semple, J. (1998) The Modified Card Sorting Test: Test-retest stability and relationships with demographic variables in a healthy older adult sample. British Journal of Clinical Psychology, 37(4), 457-466.

Fassino, S., Pieró, A., Daga, G. A., Leombruni, P., Mortara, P., \& Rovera, G. G. (2001). Attentional biases and frontal functioning in anorexia nervosa. International Journal of Eating Disorders, 31(3), 274-283.

Folstein, M. F., Folstein, S. E., \& McHugh, P. R. (1975). "Minimental state": A practical method for grading the cognitive state of patients for the clinician. Journal of Psychiatric Research, 12(3), 189-198.

Fork, M., Bartels, C., Ebert, A. D., Crubich, C., Synowitz, H., \& Wallesch, C. W. (2005) Neuropsychological sequelae of diffuse traumatic brain injury. Brain Injury, 19(2), 101-108.

Giovagnoli, A. R. (2001). Relation of sorting impairment to hippocampal damage in temporal lobe epilepsy. Neuropsychologia, 39(2), 140-150.

Grant, D. A., \& Berg, E. A. (1948). A behavioral analysis of degree of reinforcement and ease of shifting to new responses in a Weigltype card sorting problem. Journal of Experimental Psychology, 38(4), 404-411.

Greve, K. W. (2001). The WCST-64: A standardized short-form of the Wisconsin Card Sorting Test. The Clinical Neuropsychologist, 15(2), 228-234.

Greve, K. W., Bianchini, K. J., Hartley, S. M., \& Adams, D. (1999). The Wisconsin Card Sorting Test in stroke rehabilitation: Factor structure and relationship to outcome. Archives of Clinical Neuropsychology, 14(6), 497-509.

Guàrdia-Olmos, J., Peró-Cebollero, M., Rivera, D., \& ArangoLasprilla, J.C. (2015). Methodology for the development of normative data for ten Spanish-language neuropsychological tests in eleven Latin American countries. NeuroRehabilitation, 37, 493-499.

Hunkin, N., Parkin, A., \& Longmore, B. (1994). Aetiological variation in the amnesic syndrome: Comparisons using the list discrimination task. Neuropsychologia, 32(7), 819-825.

Joyce, E. \& Robbins, T. (1991). Frontal lobe function in Korsakoff and non-Korsakoff alcoholics: Planning and spatial working memory. Neuropsychologia, 29(8), 709-723.

Kroenke, K., Spitzer, R. L., \& Williams, J. B. (2001). The PHQ-9. Journal of General Internal Medicine, 16(9), 606-613.

Lineweaver, T. T., Bondi, M. W., Thomas, R. G., \& Salmon, D. P. (1999). A normative study of Nelson's (1976) modified version of the Wisconsin Card Sorting Test in healthy older adults. The Clinical Neuropsychologst, 13(3), 328-347.

Mahoney, F. I., \& Barthel, D. (1965). Functional evaluation: The Barthel Index. Maryland State Medical Journal, 14, 56-61.

Nedjam, Z., Devouche, E., \& Dalla Barba, G. (2004). Confabulation, but not executive dysfunction discriminate $\mathrm{AD}$ from frontotemporal dementia. European Journal of Neurology, 11(11), 728-733.

Nelson, H. E. (1976). A modified card sorting test sensitive to frontal lobe defects. Cortex, 12(4), 313-324.

Obonsawin, M. C., Crawford, J. R., Page, J. Chalmers, P., Low, G., \& Marsch, P. (1999). Performance on the Modified Card Sorting Test by normal, healthy individuals: Relationship to general intellectual ability and demographic variables. Journal of Clinical Psychology, 38(1), 27-41.

Paolo, A. M., Axelrod, B. N., Troster, A. I., Blackwell, K. T., \& Koller, W. C. (1996). Utility of a Wisconsin Card Sorting Test short form 
in persons with Alzheimer's and Parkinson's disease. Journal of Clinical and Experimental Neuropsychology, 18(6), 892-897.

Peinemann, A., Schuller, S., Pohl, C., Jahn, T., Weindl, A., \& Kassubek, J. (2005). Executive dysfunction in early stages of Huntington's disease is associated with striatal and insular atrophy: A neuropsychological and voxel-based morphometric study. Journal of Neurological Sciences, 239(1), 11-19.

Petrova, M., Raycheva, M., Zhelev, Y., \& Traykov, L. (2010) Executive functions deficit in Parkinson's disease with amnestic mild cognitive impairment. American Journal of Alzheimer's Disease and Other Dementias, 25(5), 455-460.

Pham, T. H., Vanderstukken, O., Philippot, P., \& Vanderlinden, M. (2003). Selective attention and executive functions deficits among criminal psychopaths. Aggressive Behavior, 29(5), 393-405.

Plumet, J., Gil, R., \& Gaonac'h, D. (2005). Neuropsychological assessment of executive functions in women: Effects of age and education. Neuropsychology, 19(5), 566-577.

Rey, G. J. Feldman, E., Rivas-Vazquez, R., Levin, B. E., \& Benton A. (1999). Neuropsychological test development and normative data on Hispanics. Archives of Clinical Neuropsychology, 14(7), 593-601.
Schretlen, D. J. (2010). Modified Wisconsin Card Sorting Test: $M$-WCST. Professional Manual. PAR.

Snowden, J., Craufurd, D., Griffiths, H., Thompson, J., \& Neary, D. (2001). Longitudinal evaluation of cognitive disorder in Huntington's disease. Journal of International Neuropsychological Society, 7(01), 33-44.

Traykov, L., Baudic, S., Raoux, N., Latour, F., Rieu, D., Smagghe, A., $\&$ Rigaud, A. S. (2005). Patterns of memory impairment and perseverative behavior discriminate early Alzheimer's disease from subcortical vascular dementia. Journal of Neurological Sciences, 229, 75-79.

Van den Broek, M., Bradshaw, C., \& Szabadi, E. (1993). Utility of the modified Wisconsin card sorting test in neuropsychological assessment. British Journal of Clinical Psychology, 32(3), 333343.

Wang, Q., Sun, J., Ma, X., Wang, Y., Yao, J., Deng, W., Liu, X., Collier, D. A., \& Li, T. (2011). Normative data on a battery of neuropsychological tests in the Han Chinese population. Journal of Neuropsychology, 5(1), 126-142. 


\section{Appendix}

Table A1

Normative data for the M-WCST Numbers of categories stratified by age and education levels for ARGENTINA

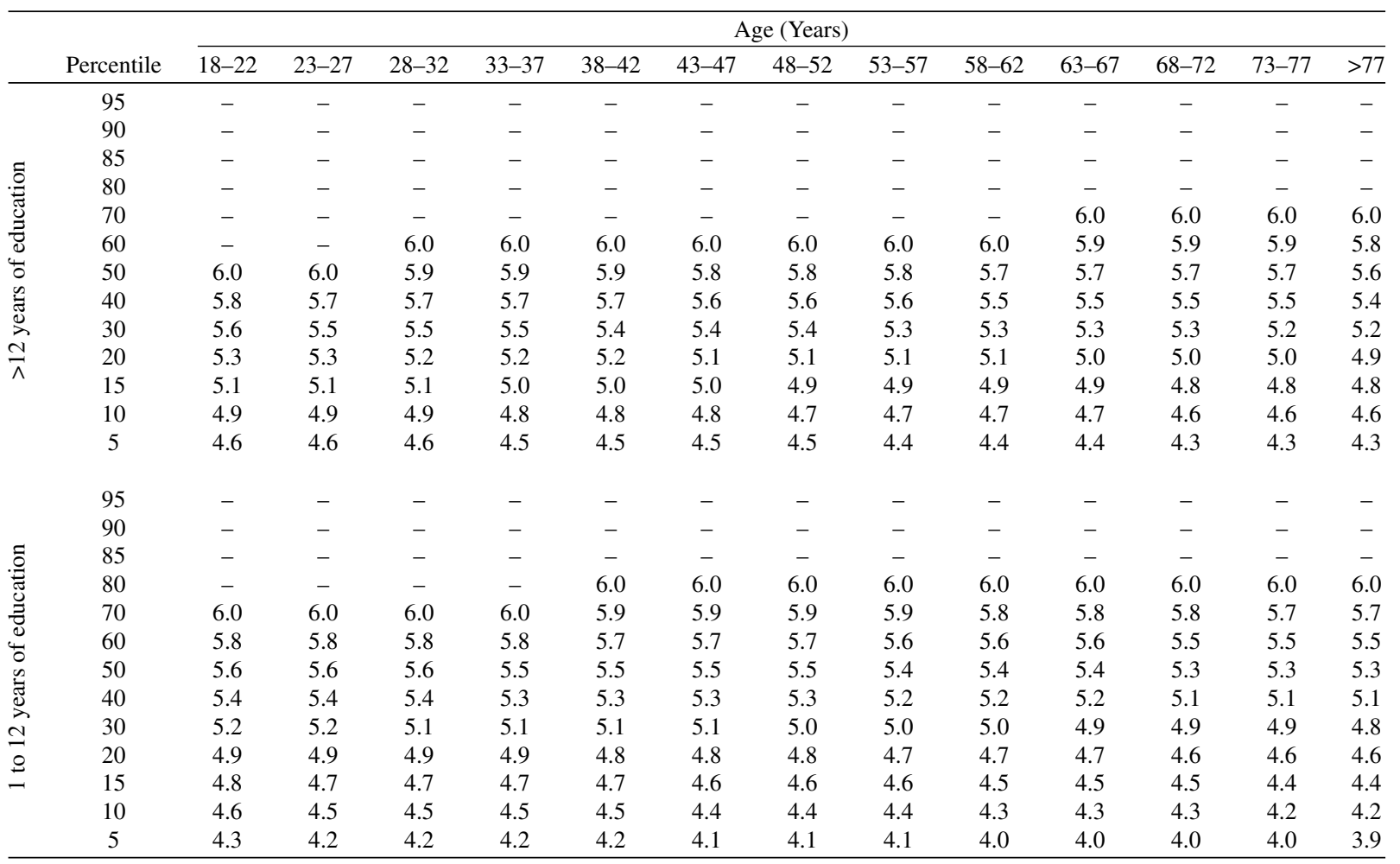

Table A2

Normative data for the M-WCST Numbers of categories stratified by age for BOLIVIA

\begin{tabular}{|c|c|c|c|c|c|c|c|c|c|c|c|c|c|}
\hline \multirow[b]{2}{*}{ Percentile } & \multicolumn{13}{|c|}{ Age (Years) } \\
\hline & $18-22$ & $23-27$ & $28-32$ & $33-37$ & $38-42$ & $43-47$ & $48-52$ & $53-57$ & $58-62$ & $63-67$ & $68-72$ & $73-77$ & $>77$ \\
\hline 95 & - & - & - & - & - & - & - & - & - & - & - & - & 6.0 \\
\hline 90 & - & - & - & - & - & - & - & - & - & 6.0 & 6.0 & 6.0 & 5.9 \\
\hline 85 & - & - & - & - & - & - & 6.0 & 6.0 & 6.0 & 5.9 & 5.8 & 5.6 & 5.5 \\
\hline 80 & - & - & 6.0 & 6.0 & 6.0 & 6.0 & 5.9 & 5.8 & 5.7 & 5.6 & 5.4 & 5.3 & 5.2 \\
\hline 70 & 6.0 & 6.0 & 5.9 & 5.8 & 5.7 & 5.5 & 5.4 & 5.3 & 5.2 & 5.0 & 4.9 & 4.8 & 4.7 \\
\hline 60 & 5.7 & 5.6 & 5.5 & 5.3 & 5.2 & 5.1 & 5.0 & 4.8 & 4.7 & 4.6 & 4.5 & 4.3 & 4.2 \\
\hline 50 & 5.3 & 5.2 & 5.0 & 4.9 & 4.8 & 4.7 & 4.5 & 4.4 & 4.3 & 4.2 & 4.0 & 3.9 & 3.8 \\
\hline 40 & 4.9 & 4.8 & 4.6 & 4.5 & 4.4 & 4.3 & 4.1 & 4.0 & 3.9 & 3.8 & 3.6 & 3.5 & 3.4 \\
\hline 30 & 4.4 & 4.3 & 4.2 & 4.1 & 3.9 & 3.8 & 3.7 & 3.6 & 3.4 & 3.3 & 3.2 & 3.1 & 2.9 \\
\hline 20 & 3.9 & 3.8 & 3.7 & 3.5 & 3.4 & 3.3 & 3.2 & 3.0 & 2.9 & 2.8 & 2.7 & 2.5 & 2.4 \\
\hline 15 & 3.6 & 3.4 & 3.3 & 3.2 & 3.1 & 2.9 & 2.8 & 2.7 & 2.6 & 2.4 & 2.3 & 2.2 & 2.1 \\
\hline 10 & 3.2 & 3.0 & 2.9 & 2.8 & 2.7 & 2.5 & 2.4 & 2.3 & 2.2 & 2.1 & 1.9 & 1.8 & 1.7 \\
\hline 5 & 2.6 & 2.5 & 2.3 & 2.2 & 2.1 & 2.0 & 1.8 & 1.7 & 1.6 & 1.5 & 1.3 & 1.2 & 1.1 \\
\hline
\end{tabular}


Table A3

Normative data for the M-WCST Numbers of categories stratified by age for CHILE

\begin{tabular}{|c|c|c|c|c|c|c|c|c|c|c|c|c|c|}
\hline \multirow[b]{2}{*}{ Percentile } & \multicolumn{13}{|c|}{ Age (Years) } \\
\hline & $18-22$ & $23-27$ & $28-32$ & $33-37$ & $38-42$ & $43-47$ & $48-52$ & $53-57$ & $58-62$ & $63-67$ & $68-72$ & $73-77$ & $>77$ \\
\hline 95 & - & - & - & - & - & - & - & - & - & - & - & - & $\overline{-}$ \\
\hline 90 & - & - & - & - & - & - & - & - & - & - & - & - & - \\
\hline 85 & - & - & - & - & - & - & - & - & - & - & - & - & 6.0 \\
\hline 80 & - & - & - & - & - & - & - & 6.0 & 6.0 & 6.0 & 6.0 & 6.0 & 5.9 \\
\hline 70 & - & - & - & 6.0 & 6.0 & 6.0 & 6.0 & 5.9 & 5.8 & 5.7 & 5.6 & 5.6 & 5.5 \\
\hline 60 & 6.0 & 6.0 & 6.0 & 5.9 & 5.8 & 5.7 & 5.7 & 5.6 & 5.5 & 5.4 & 5.3 & 5.2 & 5.1 \\
\hline 50 & 5.9 & 5.8 & 5.7 & 5.6 & 5.5 & 5.4 & 5.3 & 5.3 & 5.2 & 5.1 & 5.0 & 4.9 & 4.8 \\
\hline 40 & 5.6 & 5.5 & 5.4 & 5.3 & 5.2 & 5.1 & 5.0 & 5.0 & 4.9 & 4.8 & 4.7 & 4.6 & 4.5 \\
\hline 30 & 5.2 & 5.1 & 5.1 & 5.0 & 4.9 & 4.8 & 4.7 & 4.6 & 4.5 & 4.4 & 4.4 & 4.3 & 4.2 \\
\hline 20 & 4.8 & 4.7 & 4.7 & 4.6 & 4.5 & 4.4 & 4.3 & 4.2 & 4.1 & 4.0 & 4.0 & 3.9 & 3.8 \\
\hline 15 & 4.6 & 4.5 & 4.4 & 4.3 & 4.2 & 4.1 & 4.1 & 4.0 & 3.9 & 3.8 & 3.7 & 3.6 & 3.5 \\
\hline 10 & 4.3 & 4.2 & 4.1 & 4.0 & 3.9 & 3.9 & 3.8 & 3.7 & 3.6 & 3.5 & 3.4 & 3.3 & 3.2 \\
\hline 5 & 3.8 & 3.8 & 3.7 & 3.6 & 3.5 & 3.4 & 3.3 & 3.2 & 3.1 & 3.1 & 3.0 & 2.9 & 2.8 \\
\hline
\end{tabular}

Table A4

Normative data for the M-WCST Numbers of categories stratified by age and education levels for CUBA

\begin{tabular}{|c|c|c|c|c|c|c|c|c|c|c|c|c|c|c|}
\hline & \multirow[b]{2}{*}{ Percentile } & \multicolumn{13}{|c|}{ Age (Years) } \\
\hline & & $18-22$ & $23-27$ & $28-32$ & $33-37$ & $38-42$ & $43-47$ & $48-52$ & $53-57$ & $58-62$ & $63-67$ & $68-72$ & $73-77$ & $>77$ \\
\hline \multirow{13}{*}{ 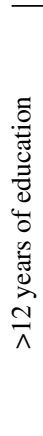 } & 95 & - & - & - & - & - & - & - & - & - & - & - & - & - \\
\hline & 90 & - & - & - & - & - & - & - & - & - & - & - & - & 6.0 \\
\hline & 85 & - & - & - & - & - & - & - & - & - & - & 6.0 & 6.0 & 5.9 \\
\hline & 80 & - & - & - & - & - & - & 6.0 & 6.0 & 6.0 & 6.0 & 5.9 & 5.8 & 5.7 \\
\hline & 70 & - & - & - & 6.0 & 6.0 & 6.0 & 5.9 & 5.8 & 5.7 & 5.6 & 5.5 & 5.3 & 5.2 \\
\hline & 60 & 6.0 & 6.0 & 6.0 & 5.9 & 5.8 & 5.7 & 5.5 & 5.4 & 5.3 & 5.2 & 5.1 & 4.9 & 4.8 \\
\hline & 50 & 5.9 & 5.8 & 5.7 & 5.6 & 5.4 & 5.3 & 5.2 & 5.1 & 5.0 & 4.8 & 4.7 & 4.6 & 4.5 \\
\hline & 40 & 5.6 & 5.4 & 5.3 & 5.2 & 5.1 & 5.0 & 4.8 & 4.7 & 4.6 & 4.5 & 4.4 & 4.2 & 4.1 \\
\hline & 30 & 5.2 & 5.1 & 4.9 & 4.8 & 4.7 & 4.6 & 4.5 & 4.3 & 4.2 & 4.1 & 4.0 & 3.9 & 3.7 \\
\hline & 20 & 4.7 & 4.6 & 4.5 & 4.4 & 4.2 & 4.1 & 4.0 & 3.9 & 3.8 & 3.6 & 3.5 & 3.4 & 3.3 \\
\hline & 15 & 4.4 & 4.3 & 4.2 & 4.1 & 4.0 & 3.8 & 3.7 & 3.6 & 3.5 & 3.4 & 3.2 & 3.1 & 3.0 \\
\hline & 10 & 4.1 & 4.0 & 3.9 & 3.7 & 3.6 & 3.5 & 3.4 & 3.3 & 3.1 & 3.0 & 2.9 & 2.8 & 2.7 \\
\hline & 5 & 3.6 & 3.5 & 3.4 & 3.2 & 3.1 & 3.0 & 2.9 & 2.8 & 2.6 & 2.5 & 2.4 & 2.3 & 2.2 \\
\hline \multirow{13}{*}{ 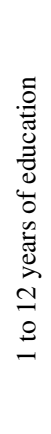 } & 95 & - & - & - & - & - & - & - & - & - & - & 6.0 & 6.0 & 6.0 \\
\hline & 90 & - & - & _ & _- & - & - & - & 6.0 & 6.0 & 6.0 & 5.9 & 5.8 & 5.7 \\
\hline & 85 & - & - & - & - & - & 6.0 & 6.0 & 5.9 & 5.8 & 5.7 & 5.6 & 5.5 & 5.3 \\
\hline & 80 & - & 6.0 & 6.0 & 6.0 & 6.0 & 5.9 & 5.8 & 5.6 & 5.5 & 5.4 & 5.3 & 5.2 & 5.0 \\
\hline & 70 & 6.0 & 5.9 & 5.8 & 5.7 & 5.6 & 5.4 & 5.3 & 5.2 & 5.1 & 5.0 & 4.8 & 4.7 & 4.6 \\
\hline & 60 & 5.7 & 5.5 & 5.4 & 5.3 & 5.2 & 5.1 & 4.9 & 4.8 & 4.7 & 4.6 & 4.5 & 4.3 & 4.2 \\
\hline & 50 & 5.3 & 5.2 & 5.1 & 4.9 & 4.8 & 4.7 & 4.6 & 4.5 & 4.3 & 4.2 & 4.1 & 4.0 & 3.9 \\
\hline & 40 & 4.9 & 4.8 & 4.7 & 4.6 & 4.5 & 4.3 & 4.2 & 4.1 & 4.0 & 3.9 & 3.7 & 3.6 & 3.5 \\
\hline & 30 & 4.6 & 4.4 & 4.3 & 4.2 & 4.1 & 4.0 & 3.8 & 3.7 & 3.6 & 3.5 & 3.4 & 3.2 & 3.1 \\
\hline & 20 & 4.1 & 4.0 & 3.9 & 3.8 & 3.6 & 3.5 & 3.4 & 3.3 & 3.2 & 3.0 & 2.9 & 2.8 & 2.7 \\
\hline & 15 & 3.8 & 3.7 & 3.6 & 3.5 & 3.4 & 3.2 & 3.1 & 3.0 & 2.9 & 2.7 & 2.6 & 2.5 & 2.4 \\
\hline & 10 & 3.5 & 3.4 & 3.3 & 3.1 & 3.0 & 2.9 & 2.8 & 2.6 & 2.5 & 2.4 & 2.3 & 2.2 & 2.0 \\
\hline & 5 & 3.0 & 2.9 & 2.7 & 2.6 & 2.5 & 2.4 & 2.3 & 2.1 & 2.0 & 1.9 & 1.8 & 1.7 & 1.5 \\
\hline
\end{tabular}


Table A5

Normative data for the M-WCST Numbers of categories stratified by age and education levels for EL SALVADOR

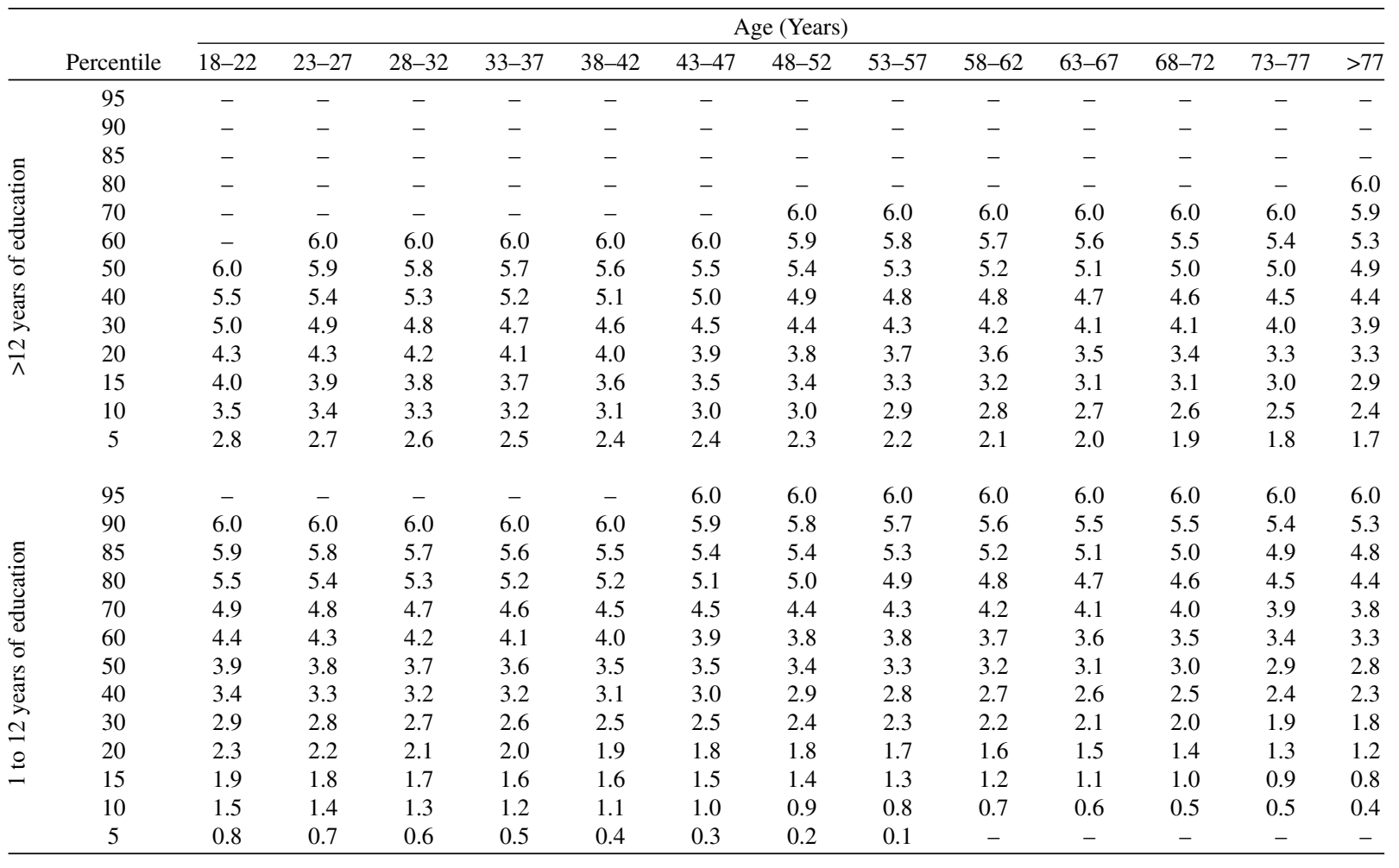

Table A6

Normative data for the M-WCST Numbers of categories stratified by education levels for GUATEMALA

\begin{tabular}{lcc}
\hline Percentile & 1 to 12 years of education & $>12$ years of education \\
\hline 95 & - & - \\
90 & 6.0 & - \\
85 & 5.7 & - \\
80 & 5.4 & - \\
70 & 4.8 & 6.0 \\
60 & 4.3 & 5.8 \\
50 & 3.9 & 5.3 \\
40 & 3.5 & 4.9 \\
30 & 3.0 & 4.5 \\
20 & 2.5 & 3.9 \\
15 & 2.2 & 3.6 \\
10 & 1.7 & 3.2 \\
5 & 1.1 & 2.5 \\
\hline
\end{tabular}


Table A7

Normative data for the M-WCST Numbers of categories stratified by age and education levels for HONDURAS

\begin{tabular}{|c|c|c|c|c|c|c|c|c|c|c|c|c|c|c|}
\hline & \multirow[b]{2}{*}{ Percentile } & \multicolumn{13}{|c|}{ Age (Years) } \\
\hline & & $18-22$ & $23-27$ & $28-32$ & $33-37$ & $38-42$ & $43-47$ & $48-52$ & $53-57$ & $58-62$ & $63-67$ & $68-72$ & $73-77$ & $>77$ \\
\hline \multirow{13}{*}{ 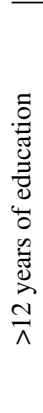 } & 95 & - & - & - & - & - & - & - & - & - & 6.0 & 6.0 & 6.0 & 6.0 \\
\hline & 90 & - & - & - & - & - & - & - & 6.0 & 6.0 & 5.9 & 5.7 & 5.5 & 5.4 \\
\hline & 85 & - & - & - & - & - & 6.0 & 6.0 & 5.9 & 5.7 & 5.5 & 5.3 & 5.1 & 4.9 \\
\hline & 80 & - & - & 6.0 & 6.0 & 6.0 & 5.9 & 5.7 & 5.5 & 5.3 & 5.1 & 4.9 & 4.8 & 4.6 \\
\hline & 70 & 6.0 & 6.0 & 5.9 & 5.7 & 5.5 & 5.3 & 5.1 & 4.9 & 4.7 & 4.6 & 4.4 & 4.2 & 4.0 \\
\hline & 60 & 5.8 & 5.6 & 5.4 & 5.2 & 5.0 & 4.8 & 4.6 & 4.4 & 4.3 & 4.1 & 3.9 & 3.7 & 3.5 \\
\hline & 50 & 5.3 & 5.1 & 4.9 & 4.8 & 4.6 & 4.4 & 4.2 & 4.0 & 3.8 & 3.6 & 3.4 & 3.2 & 3.0 \\
\hline & 40 & 4.9 & 4.7 & 4.5 & 4.3 & 4.1 & 3.9 & 3.7 & 3.5 & 3.3 & 3.2 & 3.0 & 2.8 & 2.6 \\
\hline & 30 & 4.4 & 4.2 & 4.0 & 3.8 & 3.6 & 3.4 & 3.2 & 3.1 & 2.9 & 2.7 & 2.5 & 2.3 & 2.1 \\
\hline & 20 & 3.8 & 3.6 & 3.4 & 3.2 & 3.0 & 2.9 & 2.7 & 2.5 & 2.3 & 2.1 & 1.9 & 1.7 & 1.5 \\
\hline & 15 & 3.4 & 3.2 & 3.1 & 2.9 & 2.7 & 2.5 & 2.3 & 2.1 & 1.9 & 1.7 & 1.5 & 1.4 & 1.2 \\
\hline & 10 & 3.0 & 2.8 & 2.6 & 2.4 & 2.2 & 2.1 & 1.9 & 1.7 & 1.5 & 1.3 & 1.1 & 0.9 & 0.7 \\
\hline & 5 & 2.4 & 2.2 & 2.0 & 1.8 & 1.6 & 1.4 & 1.2 & 1.0 & 0.8 & 0.6 & 0.5 & 0.3 & 0.1 \\
\hline \multirow{13}{*}{ 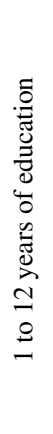 } & 95 & - & - & - & 6.0 & 6.0 & 6.0 & 6.0 & 5.8 & 5.6 & 5.4 & 5.3 & 5.1 & 4.9 \\
\hline & 90 & - & 6.0 & 6.0 & 5.9 & 5.7 & 5.6 & 5.4 & 5.2 & 5.0 & 4.8 & 4.6 & 4.4 & 4.2 \\
\hline & 85 & 6.0 & 5.9 & 5.7 & 5.5 & 5.3 & 5.1 & 4.9 & 4.7 & 4.6 & 4.4 & 4.2 & 4.0 & 3.8 \\
\hline & 80 & 5.7 & 5.5 & 5.3 & 5.1 & 5.0 & 4.8 & 4.6 & 4.4 & 4.2 & 4.0 & 3.8 & 3.6 & 3.4 \\
\hline & 70 & 5.1 & 4.9 & 4.8 & 4.6 & 4.4 & 4.2 & 4.0 & 3.8 & 3.6 & 3.4 & 3.2 & 3.0 & 2.9 \\
\hline & 60 & 4.6 & 4.5 & 4.3 & 4.1 & 3.9 & 3.7 & 3.5 & 3.3 & 3.1 & 2.9 & 2.7 & 2.6 & 2.4 \\
\hline & 50 & 4.2 & 4.0 & 3.8 & 3.6 & 3.4 & 3.2 & 3.1 & 2.9 & 2.7 & 2.5 & 2.3 & 2.1 & 1.9 \\
\hline & 40 & 3.7 & 3.5 & 3.4 & 3.2 & 3.0 & 2.8 & 2.6 & 2.4 & 2.2 & 2.0 & 1.8 & 1.7 & 1.5 \\
\hline & 30 & 3.3 & 3.1 & 2.9 & 2.7 & 2.5 & 2.3 & 2.1 & 1.9 & 1.7 & 1.5 & 1.4 & 1.2 & 1.0 \\
\hline & 20 & 2.7 & 2.5 & 2.3 & 2.1 & 1.9 & 1.7 & 1.5 & 1.3 & 1.2 & 1.0 & 0.8 & 0.6 & 0.4 \\
\hline & 15 & 2.3 & 2.1 & 1.9 & 1.7 & 1.6 & 1.4 & 1.2 & 1.0 & 0.8 & 0.6 & 0.4 & 0.2 & - \\
\hline & 10 & 1.9 & 1.7 & 1.5 & 1.3 & 1.1 & 0.9 & 0.7 & 0.5 & 0.4 & 0.2 & - & - & - \\
\hline & 5 & 1.2 & 1.0 & 0.8 & 0.7 & 0.5 & 0.3 & 0.1 & - & - & - & - & - & - \\
\hline
\end{tabular}

Table A8

Normative data for the M-WCST Numbers of categories stratified by age and education levels for MEXICO

\begin{tabular}{|c|c|c|c|c|c|c|c|c|c|c|c|c|c|c|}
\hline & \multirow[b]{2}{*}{ Percentile } & \multicolumn{13}{|c|}{ Age (Years) } \\
\hline & & $18-22$ & $23-27$ & $28-32$ & $33-37$ & $38-42$ & $43-47$ & $48-52$ & $53-57$ & $58-62$ & $63-67$ & $68-72$ & $73-77$ & $>77$ \\
\hline \multirow{13}{*}{ 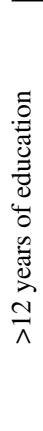 } & 95 & - & - & - & - & - & - & - & - & - & - & - & - & - \\
\hline & 90 & - & - & - & - & - & - & - & - & - & - & - & - & - \\
\hline & 85 & - & - & - & - & - & - & - & - & - & - & - & 6.0 & 6.0 \\
\hline & 80 & - & - & - & - & - & - & - & 6.0 & 6.0 & 6.0 & 6.0 & 5.9 & 5.8 \\
\hline & 70 & - & - & - & - & 6.0 & 6.0 & 6.0 & 5.9 & 5.7 & 5.6 & 5.5 & 5.4 & 5.2 \\
\hline & 60 & 6.0 & 6.0 & 6.0 & 6.0 & 5.8 & 5.7 & 5.6 & 5.4 & 5.3 & 5.2 & 5.0 & 4.9 & 4.8 \\
\hline & 50 & 5.9 & 5.8 & 5.7 & 5.5 & 5.4 & 5.3 & 5.2 & 5.0 & 4.9 & 4.8 & 4.6 & 4.5 & 4.4 \\
\hline & 40 & 5.5 & 5.4 & 5.3 & 5.1 & 5.0 & 4.9 & 4.8 & 4.6 & 4.5 & 4.4 & 4.2 & 4.1 & 4.0 \\
\hline & 30 & 5.1 & 5.0 & 4.8 & 4.7 & 4.6 & 4.4 & 4.3 & 4.2 & 4.1 & 3.9 & 3.8 & 3.7 & 3.5 \\
\hline & 20 & 4.6 & 4.4 & 4.3 & 4.2 & 4.0 & 3.9 & 3.8 & 3.7 & 3.5 & 3.4 & 3.3 & 3.1 & 3.0 \\
\hline & 15 & 4.2 & 4.1 & 4.0 & 3.9 & 3.7 & 3.6 & 3.5 & 3.3 & 3.2 & 3.1 & 2.9 & 2.8 & 2.7 \\
\hline & 10 & 3.9 & 3.7 & 3.6 & 3.5 & 3.3 & 3.2 & 3.1 & 2.9 & 2.8 & 2.7 & 2.6 & 2.4 & 2.3 \\
\hline & 5 & 3.3 & 3.1 & 3.0 & 2.9 & 2.7 & 2.6 & 2.5 & 2.4 & 2.2 & 2.1 & 2.0 & 1.8 & 1.7 \\
\hline \multirow{13}{*}{ 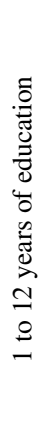 } & 95 & - & - & - & - & - & - & - & - & - & - & - & 6.0 & 6.0 \\
\hline & 90 & - & - & - & - & - & - & - & - & 6.0 & 6.0 & 6.0 & 5.9 & 5.8 \\
\hline & 85 & - & - & - & - & - & - & 6.0 & 6.0 & 5.9 & 5.8 & 5.7 & 5.5 & 5.4 \\
\hline & 80 & - & - & 6.0 & 6.0 & 6.0 & 6.0 & 5.9 & 5.7 & 5.6 & 5.5 & 5.4 & 5.2 & 5.1 \\
\hline & 70 & 6.0 & 6.0 & 5.9 & 5.7 & 5.6 & 5.5 & 5.3 & 5.2 & 5.1 & 5.0 & 4.8 & 4.7 & 4.6 \\
\hline & 60 & 5.7 & 5.6 & 5.4 & 5.3 & 5.2 & 5.0 & 4.9 & 4.8 & 4.6 & 4.5 & 4.4 & 4.3 & 4.1 \\
\hline & 50 & 5.3 & 5.1 & 5.0 & 4.9 & 4.8 & 4.6 & 4.5 & 4.4 & 4.2 & 4.1 & 4.0 & 3.9 & 3.7 \\
\hline & 40 & 4.9 & 4.7 & 4.6 & 4.5 & 4.4 & 4.2 & 4.1 & 4.0 & 3.8 & 3.7 & 3.6 & 3.4 & 3.3 \\
\hline & 30 & 4.4 & 4.3 & 4.2 & 4.0 & 3.9 & 3.8 & 3.7 & 3.5 & 3.4 & 3.3 & 3.1 & 3.0 & 2.9 \\
\hline & 20 & 3.9 & 3.8 & 3.7 & 3.5 & 3.4 & 3.3 & 3.1 & 3.0 & 2.9 & 2.7 & 2.6 & 2.5 & 2.4 \\
\hline & 15 & 3.6 & 3.5 & 3.3 & 3.2 & 3.1 & 2.9 & 2.8 & 2.7 & 2.5 & 2.4 & 2.3 & 2.2 & 2.0 \\
\hline & 10 & 3.2 & 3.1 & 2.9 & 2.8 & 2.7 & 2.5 & 2.4 & 2.3 & 2.2 & 2.0 & 1.9 & 1.8 & 1.6 \\
\hline & 5 & 2.6 & 2.5 & 2.3 & 2.2 & 2.1 & 2.0 & 1.8 & 1.7 & 1.6 & 1.4 & 1.3 & 1.2 & 1.1 \\
\hline
\end{tabular}


Table A9

Normative data for the M-WCST Numbers of categories stratified by age and education levels for PARAGUAY

\begin{tabular}{|c|c|c|c|c|c|c|c|c|c|c|c|c|c|c|}
\hline & \multirow[b]{2}{*}{ Percentile } & \multicolumn{13}{|c|}{ Age (Years) } \\
\hline & & $18-22$ & $23-27$ & $28-32$ & $33-37$ & $38-42$ & $43-47$ & $48-52$ & $53-57$ & $58-62$ & $63-67$ & $68-72$ & $73-77$ & $>77$ \\
\hline \multirow{13}{*}{ 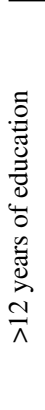 } & 95 & - & - & - & - & - & - & - & - & - & - & - & - & - \\
\hline & 90 & - & - & - & - & - & - & - & - & - & - & - & 6.0 & 6.0 \\
\hline & 85 & - & - & - & - & - & - & - & - & - & 6.0 & 6.0 & 5.9 & 5.8 \\
\hline & 80 & - & - & - & - & - & - & 6.0 & 6.0 & 6.0 & 5.9 & 5.8 & 5.7 & 5.6 \\
\hline & 70 & - & - & - & 6.0 & 6.0 & 6.0 & 5.9 & 5.8 & 5.7 & 5.6 & 5.5 & 5.4 & 5.4 \\
\hline & 60 & - & 6.0 & 6.0 & 5.9 & 5.8 & 5.7 & 5.7 & 5.6 & 5.5 & 5.4 & 5.3 & 5.2 & 5.1 \\
\hline & 50 & 6.0 & 5.9 & 5.8 & 5.7 & 5.6 & 5.5 & 5.4 & 5.4 & 5.3 & 5.2 & 5.1 & 5.0 & 4.9 \\
\hline & 40 & 5.8 & 5.7 & 5.6 & 5.5 & 5.4 & 5.3 & 5.2 & 5.2 & 5.1 & 5.0 & 4.9 & 4.8 & 4.7 \\
\hline & 30 & 5.5 & 5.5 & 5.4 & 5.3 & 5.2 & 5.1 & 5.0 & 4.9 & 4.9 & 4.8 & 4.7 & 4.6 & 4.5 \\
\hline & 20 & 5.3 & 5.2 & 5.1 & 5.0 & 4.9 & 4.8 & 4.8 & 4.7 & 4.6 & 4.5 & 4.4 & 4.3 & 4.2 \\
\hline & 15 & 5.1 & 5.0 & 4.9 & 4.9 & 4.8 & 4.7 & 4.6 & 4.5 & 4.4 & 4.3 & 4.3 & 4.2 & 4.1 \\
\hline & 10 & 4.9 & 4.8 & 4.7 & 4.7 & 4.6 & 4.5 & 4.4 & 4.3 & 4.2 & 4.1 & 4.1 & 4.0 & 3.9 \\
\hline & 5 & 4.6 & 4.5 & 4.4 & 4.4 & 4.3 & 4.2 & 4.1 & 4.0 & 3.9 & 3.8 & 3.8 & 3.7 & 3.6 \\
\hline \multirow{13}{*}{ 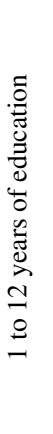 } & 95 & - & - & - & - & - & - & 6.0 & 6.0 & 6.0 & 6.0 & 5.9 & 5.8 & 5.7 \\
\hline & 90 & - & - & - & - & 6.0 & 6.0 & 5.9 & 5.9 & 5.8 & 5.7 & 5.6 & 5.5 & 5.4 \\
\hline & 85 & - & - & 6.0 & 6.0 & 5.9 & 5.8 & 5.7 & 5.7 & 5.6 & 5.5 & 5.4 & 5.3 & 5.2 \\
\hline & 80 & 6.0 & 6.0 & 5.9 & 5.8 & 5.8 & 5.7 & 5.6 & 5.5 & 5.4 & 5.3 & 5.2 & 5.2 & 5.1 \\
\hline & 70 & 5.8 & 5.8 & 5.7 & 5.6 & 5.5 & 5.4 & 5.3 & 5.2 & 5.1 & 5.1 & 5.0 & 4.9 & 4.8 \\
\hline & 60 & 5.6 & 5.5 & 5.4 & 5.4 & 5.3 & 5.2 & 5.1 & 5.0 & 4.9 & 4.8 & 4.8 & 4.7 & 4.6 \\
\hline & 50 & 5.4 & 5.3 & 5.2 & 5.2 & 5.1 & 5.0 & 4.9 & 4.8 & 4.7 & 4.6 & 4.6 & 4.5 & 4.4 \\
\hline & 40 & 5.2 & 5.1 & 5.0 & 4.9 & 4.9 & 4.8 & 4.7 & 4.6 & 4.5 & 4.4 & 4.3 & 4.3 & 4.2 \\
\hline & 30 & 5.0 & 4.9 & 4.8 & 4.7 & 4.6 & 4.6 & 4.5 & 4.4 & 4.3 & 4.2 & 4.1 & 4.0 & 4.0 \\
\hline & 20 & 4.7 & 4.6 & 4.6 & 4.5 & 4.4 & 4.3 & 4.2 & 4.1 & 4.0 & 3.9 & 3.9 & 3.8 & 3.7 \\
\hline & 15 & 4.6 & 4.5 & 4.4 & 4.3 & 4.2 & 4.1 & 4.0 & 4.0 & 3.9 & 3.8 & 3.7 & 3.6 & 3.5 \\
\hline & 10 & 4.4 & 4.3 & 4.2 & 4.1 & 4.0 & 3.9 & 3.8 & 3.8 & 3.7 & 3.6 & 3.5 & 3.4 & 3.3 \\
\hline & 5 & 4.1 & 4.0 & 3.9 & 3.8 & 3.7 & 3.6 & 3.6 & 3.5 & 3.4 & 3.3 & 3.2 & 3.1 & 3.0 \\
\hline
\end{tabular}

Table A10

Normative data for the M-WCST Numbers of categories stratified by age and education levels for PERU

\begin{tabular}{|c|c|c|c|c|c|c|c|c|c|c|c|c|c|c|}
\hline & \multirow[b]{2}{*}{ Percentile } & \multicolumn{13}{|c|}{ Age (Years) } \\
\hline & & $18-22$ & $23-27$ & $28-32$ & $33-37$ & $38-42$ & $43-47$ & $48-52$ & $53-57$ & $58-62$ & $63-67$ & $68-72$ & $73-77$ & $>77$ \\
\hline \multirow{13}{*}{ 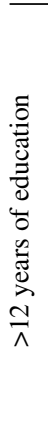 } & 95 & - & - & - & - & - & - & - & - & - & - & 6.0 & 6.0 & 6.0 \\
\hline & 90 & - & - & - & - & - & - & - & - & 6.0 & 6.0 & 5.8 & 5.7 & 5.5 \\
\hline & 85 & - & - & - & - & - & - & 6.0 & 6.0 & 5.8 & 5.7 & 5.5 & 5.3 & 5.2 \\
\hline & 80 & - & - & - & - & 6.0 & 6.0 & 5.9 & 5.7 & 5.6 & 5.4 & 5.2 & 5.1 & 4.9 \\
\hline & 70 & - & 6.0 & 6.0 & 6.0 & 5.8 & 5.6 & 5.5 & 5.3 & 5.1 & 5.0 & 4.8 & 4.6 & 4.5 \\
\hline & 60 & 6.0 & 5.9 & 5.8 & 5.6 & 5.4 & 5.3 & 5.1 & 4.9 & 4.8 & 4.6 & 4.4 & 4.3 & 4.1 \\
\hline & 50 & 5.7 & 5.6 & 5.4 & 5.2 & 5.1 & 4.9 & 4.8 & 4.6 & 4.4 & 4.3 & 4.1 & 3.9 & 3.8 \\
\hline & 40 & 5.4 & 5.2 & 5.1 & 4.9 & 4.7 & 4.6 & 4.4 & 4.2 & 4.1 & 3.9 & 3.8 & 3.6 & 3.4 \\
\hline & 30 & 5.0 & 4.9 & 4.7 & 4.5 & 4.4 & 4.2 & 4.0 & 3.9 & 3.7 & 3.6 & 3.4 & 3.2 & 3.1 \\
\hline & 20 & 4.6 & 4.4 & 4.3 & 4.1 & 3.9 & 3.8 & 3.6 & 3.4 & 3.3 & 3.1 & 3.0 & 2.8 & 2.6 \\
\hline & 15 & 4.3 & 4.2 & 4.0 & 3.8 & 3.7 & 3.5 & 3.3 & 3.2 & 3.0 & 2.8 & 2.7 & 2.5 & 2.4 \\
\hline & 10 & 4.0 & 3.8 & 3.7 & 3.5 & 3.3 & 3.2 & 3.0 & 2.9 & 2.7 & 2.5 & 2.4 & 2.2 & 2.0 \\
\hline & 5 & 3.5 & 3.3 & 3.2 & 3.0 & 2.9 & 2.7 & 2.5 & 2.4 & 2.2 & 2.0 & 1.9 & 1.7 & 1.5 \\
\hline \multirow{13}{*}{ 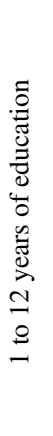 } & 95 & - & - & - & 6.0 & 6.0 & 6.0 & 5.8 & 5.7 & 5.5 & 5.3 & 5.2 & 5.0 & 4.8 \\
\hline & 90 & - & 6.0 & 6.0 & 5.8 & 5.7 & 5.5 & 5.3 & 5.2 & 5.0 & 4.9 & 4.7 & 4.5 & 4.4 \\
\hline & 85 & 6.0 & 5.8 & 5.7 & 5.5 & 5.4 & 5.2 & 5.0 & 4.9 & 4.7 & 4.5 & 4.4 & 4.2 & 4.0 \\
\hline & 80 & 5.7 & 5.6 & 5.4 & 5.2 & 5.1 & 4.9 & 4.7 & 4.6 & 4.4 & 4.3 & 4.1 & 3.9 & 3.8 \\
\hline & 70 & 5.3 & 5.1 & 5.0 & 4.8 & 4.6 & 4.5 & 4.3 & 4.2 & 4.0 & 3.8 & 3.7 & 3.5 & 3.3 \\
\hline & 60 & 4.9 & 4.8 & 4.6 & 4.4 & 4.3 & 4.1 & 3.9 & 3.8 & 3.6 & 3.5 & 3.3 & 3.1 & 3.0 \\
\hline & 50 & 4.6 & 4.4 & 4.3 & 4.1 & 3.9 & 3.8 & 3.6 & 3.4 & 3.3 & 3.1 & 3.0 & 2.8 & 2.6 \\
\hline & 40 & 4.3 & 4.1 & 3.9 & 3.8 & 3.6 & 3.4 & 3.3 & 3.1 & 2.9 & 2.8 & 2.6 & 2.4 & 2.3 \\
\hline & 30 & 3.9 & 3.7 & 3.6 & 3.4 & 3.2 & 3.1 & 2.9 & 2.7 & 2.6 & 2.4 & 2.2 & 2.1 & 1.9 \\
\hline & 20 & 3.5 & 3.3 & 3.1 & 3.0 & 2.8 & 2.6 & 2.5 & 2.3 & 2.1 & 2.0 & 1.8 & 1.6 & 1.5 \\
\hline & 15 & 3.2 & 3.0 & 2.9 & 2.7 & 2.5 & 2.4 & 2.2 & 2.0 & 1.9 & 1.7 & 1.5 & 1.4 & 1.2 \\
\hline & 10 & 2.9 & 2.7 & 2.5 & 2.4 & 2.2 & 2.0 & 1.9 & 1.7 & 1.5 & 1.4 & 1.2 & 1.0 & 0.9 \\
\hline & 5 & 2.4 & 2.2 & 2.0 & 1.9 & 1.7 & 1.5 & 1.4 & 1.2 & 1.1 & 0.9 & 0.7 & 0.6 & 0.4 \\
\hline
\end{tabular}


Table A11

Normative data for the M-WCST Numbers of categories stratified by age and education levels for PUERTO RICO

\begin{tabular}{|c|c|c|c|c|c|c|c|c|c|c|c|c|c|c|}
\hline & \multirow[b]{2}{*}{ Percentile } & \multicolumn{13}{|c|}{ Age (Years) } \\
\hline & & $18-22$ & $23-27$ & $28-32$ & $33-37$ & $38-42$ & $43-47$ & $48-52$ & $53-57$ & $58-62$ & $63-67$ & $68-72$ & $73-77$ & $>77$ \\
\hline \multirow{13}{*}{ 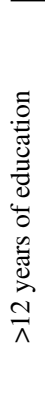 } & 95 & - & - & - & - & - & - & - & - & - & - & - & - & - \\
\hline & 90 & - & - & - & - & - & - & - & - & - & - & - & - & 6.0 \\
\hline & 85 & - & - & - & - & - & - & - & - & - & - & - & 6.0 & 5.9 \\
\hline & 80 & - & - & - & - & - & - & - & 6.0 & 6.0 & 6.0 & 6.0 & 5.8 & 5.7 \\
\hline & 70 & - & - & - & - & - & 6.0 & 6.0 & 5.9 & 5.8 & 5.6 & 5.5 & 5.4 & 5.2 \\
\hline & 60 & - & - & 6.0 & 6.0 & 6.0 & 5.8 & 5.7 & 5.6 & 5.4 & 5.3 & 5.1 & 5.0 & 4.8 \\
\hline & 50 & 6.0 & 6.0 & 5.9 & 5.8 & 5.6 & 5.5 & 5.4 & 5.2 & 5.1 & 4.9 & 4.8 & 4.6 & 4.5 \\
\hline & 40 & 5.9 & 5.7 & 5.6 & 5.4 & 5.3 & 5.2 & 5.0 & 4.9 & 4.7 & 4.6 & 4.4 & 4.3 & 4.2 \\
\hline & 30 & 5.5 & 5.3 & 5.2 & 5.1 & 4.9 & 4.8 & 4.6 & 4.5 & 4.3 & 4.2 & 4.1 & 3.9 & 3.8 \\
\hline & 20 & 5.0 & 4.9 & 4.8 & 4.6 & 4.5 & 4.3 & 4.2 & 4.0 & 3.9 & 3.8 & 3.6 & 3.5 & 3.3 \\
\hline & 15 & 4.8 & 4.6 & 4.5 & 4.3 & 4.2 & 4.1 & 3.9 & 3.8 & 3.6 & 3.5 & 3.3 & 3.2 & 3.1 \\
\hline & 10 & 4.4 & 4.3 & 4.1 & 4.0 & 3.9 & 3.7 & 3.6 & 3.4 & 3.3 & 3.2 & 3.0 & 2.9 & 2.7 \\
\hline & 5 & 3.9 & 3.8 & 3.6 & 3.5 & 3.4 & 3.2 & 3.1 & 2.9 & 2.8 & 2.7 & 2.5 & 2.4 & 2.2 \\
\hline \multirow{13}{*}{ 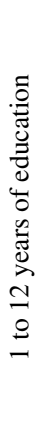 } & 95 & - & - & - & - & - & - & - & - & - & - & - & - & 6.0 \\
\hline & 90 & - & - & - & - & - & - & - & - & - & - & 6.0 & 6.0 & 5.9 \\
\hline & 85 & - & - & - & - & - & - & - & - & 6.0 & 6.0 & 5.8 & 5.7 & 5.5 \\
\hline & 80 & - & - & - & - & 6.0 & 6.0 & 6.0 & 6.0 & 5.8 & 5.7 & 5.5 & 5.4 & 5.3 \\
\hline & 70 & - & - & 6.0 & 6.0 & 5.9 & 5.8 & 5.7 & 5.5 & 5.4 & 5.2 & 5.1 & 5.0 & 4.8 \\
\hline & 60 & 6.0 & 6.0 & 5.9 & 5.7 & 5.6 & 5.4 & 5.3 & 5.1 & 5.0 & 4.9 & 4.7 & 4.6 & 4.4 \\
\hline & 50 & 5.8 & 5.7 & 5.5 & 5.4 & 5.2 & 5.1 & 4.9 & 4.8 & 4.7 & 4.5 & 4.4 & 4.2 & 4.1 \\
\hline & 40 & 5.5 & 5.3 & 5.2 & 5.0 & 4.9 & 4.7 & 4.6 & 4.5 & 4.3 & 4.2 & 4.0 & 3.9 & 3.7 \\
\hline & 30 & 5.1 & 4.9 & 4.8 & 4.6 & 4.5 & 4.4 & 4.2 & 4.1 & 3.9 & 3.8 & 3.7 & 3.5 & 3.4 \\
\hline & 20 & 4.6 & 4.5 & 4.3 & 4.2 & 4.1 & 3.9 & 3.8 & 3.6 & 3.5 & 3.3 & 3.2 & 3.1 & 2.9 \\
\hline & 15 & 4.4 & 4.2 & 4.1 & 3.9 & 3.8 & 3.6 & 3.5 & 3.4 & 3.2 & 3.1 & 2.9 & 2.8 & 2.6 \\
\hline & 10 & 4.0 & 3.9 & 3.7 & 3.6 & 3.5 & 3.3 & 3.2 & 3.0 & 2.9 & 2.7 & 2.6 & 2.5 & 2.3 \\
\hline & 5 & 3.5 & 3.4 & 3.2 & 3.1 & 3.0 & 2.8 & 2.7 & 2.5 & 2.4 & 2.2 & 2.1 & 2.0 & 1.8 \\
\hline
\end{tabular}

Table A12

Normative data for the M-WCST Perseveration errors stratified by age and education levels for ARGENTINA

\begin{tabular}{|c|c|c|c|c|c|c|c|c|c|c|c|c|c|c|}
\hline & \multirow[b]{2}{*}{ Percentile } & \multicolumn{13}{|c|}{ Age (Years) } \\
\hline & & $18-22$ & $23-27$ & $28-32$ & $33-37$ & $38-42$ & $43-47$ & $48-52$ & $53-57$ & $58-62$ & $63-67$ & $68-72$ & $73-77$ & $>77$ \\
\hline \multirow{13}{*}{ 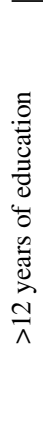 } & 95 & - & - & - & - & - & - & - & - & - & - & - & - & - \\
\hline & 90 & - & - & - & - & - & - & - & - & - & - & - & - & - \\
\hline & 85 & - & - & - & - & - & - & - & - & - & - & - & - & - \\
\hline & 80 & - & - & - & - & - & - & - & - & - & - & 0.0 & 0.1 & 0.3 \\
\hline & 70 & - & - & - & 0.0 & 0.2 & 0.3 & 0.5 & 0.7 & 0.9 & 1.1 & 1.2 & 1.4 & 1.6 \\
\hline & 60 & 0.6 & 0.8 & 0.9 & 1.1 & 1.3 & 1.5 & 1.7 & 1.8 & 2.0 & 2.2 & 2.4 & 2.6 & 2.7 \\
\hline & 50 & 1.6 & 1.8 & 2.0 & 2.2 & 2.3 & 2.5 & 2.7 & 2.9 & 3.1 & 3.2 & 3.4 & 3.6 & 3.8 \\
\hline & 40 & 2.7 & 2.9 & 3.0 & 3.2 & 3.4 & 3.6 & 3.8 & 3.9 & 4.1 & 4.3 & 4.5 & 4.7 & 4.8 \\
\hline & 30 & 3.8 & 4.0 & 4.2 & 4.4 & 4.5 & 4.7 & 4.9 & 5.1 & 5.2 & 5.4 & 5.6 & 5.8 & 6.0 \\
\hline & 20 & 5.2 & 5.3 & 5.5 & 5.7 & 5.9 & 6.1 & 6.2 & 6.4 & 6.6 & 6.8 & 6.9 & 7.1 & 7.3 \\
\hline & 15 & 6.0 & 6.2 & 6.4 & 6.5 & 6.7 & 6.9 & 7.1 & 7.3 & 7.4 & 7.6 & 7.8 & 8.0 & 8.1 \\
\hline & 10 & 7.0 & 7.2 & 7.4 & 7.5 & 7.7 & 7.9 & 8.1 & 8.3 & 8.4 & 8.6 & 8.8 & 9.0 & 9.2 \\
\hline & 5 & 8.5 & 8.7 & 8.9 & 9.1 & 9.2 & 9.4 & 9.6 & 9.8 & 9.9 & 10.1 & 10.3 & 10.5 & 10.7 \\
\hline \multirow{13}{*}{ 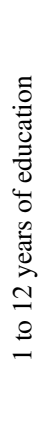 } & 95 & - & - & - & - & - & - & - & - & - & - & - & - & - \\
\hline & 90 & - & - & - & - & - & - & - & 0.0 & 0.2 & 0.3 & 0.5 & 0.7 & 0.9 \\
\hline & 85 & - & 0.0 & 0.1 & 0.3 & 0.5 & 0.6 & 0.8 & 1.0 & 1.2 & 1.4 & 1.5 & 1.7 & 1.9 \\
\hline & 80 & 0.6 & 0.8 & 0.9 & 1.1 & 1.3 & 1.5 & 1.7 & 1.8 & 2.0 & 2.2 & 2.4 & 2.5 & 2.7 \\
\hline & 70 & 1.9 & 2.1 & 2.3 & 2.5 & 2.6 & 2.8 & 3.0 & 3.2 & 3.4 & 3.5 & 3.7 & 3.9 & 4.1 \\
\hline & 60 & 3.1 & 3.2 & 3.4 & 3.6 & 3.8 & 3.9 & 4.1 & 4.3 & 4.5 & 4.7 & 4.8 & 5.0 & 5.2 \\
\hline & 50 & 4.1 & 4.3 & 4.5 & 4.6 & 4.8 & 5.0 & 5.2 & 5.4 & 5.5 & 5.7 & 5.9 & 6.1 & 6.3 \\
\hline & 40 & 5.1 & 5.3 & 5.5 & 5.7 & 5.9 & 6.0 & 6.2 & 6.4 & 6.6 & 6.8 & 6.9 & 7.1 & 7.3 \\
\hline & 30 & 6.3 & 6.5 & 6.6 & 6.8 & 7.0 & 7.2 & 7.4 & 7.5 & 7.7 & 7.9 & 8.1 & 8.3 & 8.4 \\
\hline & 20 & 7.6 & 7.8 & 8.0 & 8.2 & 8.3 & 8.5 & 8.7 & 8.9 & 9.1 & 9.2 & 9.4 & 9.6 & 9.8 \\
\hline & 15 & 8.5 & 8.6 & 8.8 & 9.0 & 9.2 & 9.4 & 9.5 & 9.7 & 9.9 & 10.1 & 10.3 & 10.4 & 10.6 \\
\hline & 10 & 9.5 & 9.7 & 9.8 & 10.0 & 10.2 & 10.4 & 10.5 & 10.7 & 10.9 & 11.1 & 11.3 & 11.4 & 11.6 \\
\hline & 5 & 11.0 & 11.2 & 11.3 & 11.5 & 11.7 & 11.9 & 12.1 & 12.2 & 12.4 & 12.6 & 12.8 & 13.0 & 13.1 \\
\hline
\end{tabular}


Table A13

Normative data for the M-WCST Perseveration errors stratified by age for BOLIVIA

\begin{tabular}{|c|c|c|c|c|c|c|c|c|c|c|c|c|c|}
\hline \multirow[b]{2}{*}{ Percentile } & \multicolumn{13}{|c|}{ Age (Years) } \\
\hline & $18-22$ & $23-27$ & $28-32$ & $33-37$ & $38-42$ & $43-47$ & $48-52$ & $53-57$ & $58-62$ & $63-67$ & $68-72$ & $73-77$ & $>77$ \\
\hline 95 & - & - & - & - & - & - & - & - & - & - & - & - & - \\
\hline 90 & - & - & - & - & - & - & - & - & - & - & - & 0.4 & 1.0 \\
\hline 85 & - & - & - & - & - & - & - & 0.0 & 0.4 & 1.0 & 1.5 & 2.1 & 2.6 \\
\hline 80 & - & - & - & - & 0.0 & 0.2 & 0.7 & 1.2 & 1.8 & 2.3 & 2.9 & 3.4 & 3.9 \\
\hline 70 & 0.0 & 0.2 & 0.7 & 1.2 & 1.8 & 2.3 & 2.9 & 3.4 & 3.9 & 4.5 & 5.0 & 5.6 & 6.1 \\
\hline 60 & 1.4 & 2.0 & 2.5 & 3.1 & 3.6 & 4.1 & 4.7 & 5.2 & 5.8 & 6.3 & 6.8 & 7.4 & 7.9 \\
\hline 50 & 3.1 & 3.7 & 4.2 & 4.8 & 5.3 & 5.8 & 6.4 & 6.9 & 7.5 & 8.0 & 8.5 & 9.1 & 9.6 \\
\hline 40 & 4.8 & 5.4 & 5.9 & 6.4 & 7.0 & 7.5 & 8.1 & 8.6 & 9.1 & 9.7 & 10.2 & 10.8 & 11.3 \\
\hline 30 & 6.6 & 7.2 & 7.7 & 8.3 & 8.8 & 9.3 & 9.9 & 10.4 & 11.0 & 11.5 & 12.0 & 12.6 & 13.1 \\
\hline 20 & 8.8 & 9.3 & 9.9 & 10.4 & 11.0 & 11.5 & 12.0 & 12.6 & 13.1 & 13.7 & 14.2 & 14.7 & 15.3 \\
\hline 15 & 10.1 & 10.7 & 11.2 & 11.8 & 12.3 & 12.8 & 13.4 & 13.9 & 14.5 & 15.0 & 15.5 & 16.1 & 16.6 \\
\hline 10 & 11.8 & 12.3 & 12.8 & 13.4 & 13.9 & 14.5 & 15.0 & 15.5 & 16.1 & 16.6 & 17.2 & 17.7 & 18.2 \\
\hline 5 & 14.2 & 14.7 & 15.3 & 15.8 & 16.4 & 16.9 & 17.4 & 18.0 & 18.5 & 19.1 & 19.6 & 20.1 & 20.7 \\
\hline
\end{tabular}

Table A14

Normative data for the M-WCST Perseveration errors stratified by age for CHILE

\begin{tabular}{lccccccccccccc}
\hline & \multicolumn{10}{c}{ Age (Years) } \\
\cline { 2 - 27 } Percentile & $18-22$ & $23-27$ & $28-32$ & $33-37$ & $38-42$ & $43-47$ & $48-52$ & $53-57$ & $58-62$ & $63-67$ & $68-72$ & $73-77$ & $>77$ \\
\hline 95 & - & - & - & - & - & - & - & - & - & - & - & - & - \\
90 & - & - & - & - & - & - & - & - & - & - & - & - & - \\
85 & - & - & - & - & - & - & - & - & - & - & - & - & - \\
80 & - & - & - & - & - & - & - & - & - & - & - & - & - \\
70 & - & - & - & - & - & - & 0.0 & 0.1 & 0.3 & 0.5 & 0.7 & 0.9 & 1.1 \\
60 & 0.1 & 0.3 & 0.4 & 0.6 & 0.8 & 1.0 & 1.2 & 1.4 & 1.6 & 1.8 & 1.9 & 2.1 & 2.3 \\
50 & 1.2 & 1.4 & 1.6 & 1.8 & 2.0 & 2.1 & 2.3 & 2.5 & 2.7 & 2.9 & 3.1 & 3.3 & 3.5 \\
40 & 2.3 & 2.5 & 2.7 & 2.9 & 3.1 & 3.3 & 3.5 & 3.7 & 3.8 & 4.0 & 4.2 & 4.4 & 4.6 \\
30 & 3.6 & 3.8 & 3.9 & 4.1 & 4.3 & 4.5 & 4.7 & 4.9 & 5.1 & 5.3 & 5.4 & 5.6 & 5.8 \\
20 & 5.0 & 5.2 & 5.4 & 5.6 & 5.8 & 6.0 & 6.1 & 6.3 & 6.5 & 6.7 & 6.9 & 7.1 & 7.3 \\
15 & 5.9 & 6.1 & 6.3 & 6.5 & 6.7 & 6.9 & 7.1 & 7.2 & 7.4 & 7.6 & 7.8 & 8.0 & 8.2 \\
10 & 7.0 & 7.2 & 7.4 & 7.6 & 7.8 & 8.0 & 8.1 & 8.3 & 8.5 & 8.7 & 8.9 & 9.1 & 9.3 \\
5 & 8.7 & 8.8 & 9.0 & 9.2 & 9.4 & 9.6 & 9.8 & 10.0 & 10.2 & 10.3 & 10.5 & 10.7 & 10.9 \\
\hline
\end{tabular}


Table A15

Normative data for the M-WCST Perseveration errors stratified by age and education levels for CUBA

\begin{tabular}{|c|c|c|c|c|c|c|c|c|c|c|c|c|c|c|}
\hline & \multirow[b]{2}{*}{ Percentile } & \multicolumn{13}{|c|}{ Age (Years) } \\
\hline & & $18-22$ & $23-27$ & $28-32$ & $33-37$ & $38-42$ & $43-47$ & $48-52$ & $53-57$ & $58-62$ & $63-67$ & $68-72$ & $73-77$ & $>77$ \\
\hline \multirow{13}{*}{ 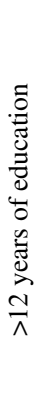 } & 95 & - & - & - & - & - & - & - & - & - & - & - & - & - \\
\hline & 90 & - & - & - & - & - & - & - & - & - & - & - & - & - \\
\hline & 85 & - & - & - & - & - & - & - & - & - & - & - & - & - \\
\hline & 80 & - & - & - & - & - & - & - & - & - & - & - & - & 0.2 \\
\hline & 70 & - & - & - & - & - & 0.0 & 0.1 & 0.4 & 0.8 & 1.2 & 1.6 & 2.0 & 2.3 \\
\hline & 60 & - & 0.0 & 0.3 & 0.7 & 1.1 & 1.4 & 1.8 & 2.2 & 2.6 & 3.0 & 3.3 & 3.7 & 4.1 \\
\hline & 50 & 1.2 & 1.6 & 1.9 & 2.3 & 2.7 & 3.1 & 3.5 & 3.8 & 4.2 & 4.6 & 5.0 & 5.3 & 5.7 \\
\hline & 40 & 2.8 & 3.2 & 3.6 & 3.9 & 4.3 & 4.7 & 5.1 & 5.5 & 5.8 & 6.2 & 6.6 & 7.0 & 7.3 \\
\hline & 30 & 4.6 & 4.9 & 5.3 & 5.7 & 6.1 & 6.5 & 6.8 & 7.2 & 7.6 & 8.0 & 8.3 & 8.7 & 9.1 \\
\hline & 20 & 6.7 & 7.0 & 7.4 & 7.8 & 8.2 & 8.5 & 8.9 & 9.3 & 9.7 & 10.0 & 10.4 & 10.8 & 11.2 \\
\hline & 15 & 8.0 & 8.3 & 8.7 & 9.1 & 9.5 & 9.8 & 10.2 & 10.6 & 11.0 & 11.4 & 11.7 & 12.1 & 12.5 \\
\hline & 10 & 9.5 & 9.9 & 10.3 & 10.6 & 11.0 & 11.4 & 11.8 & 12.2 & 12.5 & 12.9 & 13.3 & 13.7 & 14.0 \\
\hline & 5 & 11.9 & 12.2 & 12.6 & 13.0 & 13.4 & 13.7 & 14.1 & 14.5 & 14.9 & 15.3 & 15.6 & 16.0 & 16.4 \\
\hline \multirow{13}{*}{ 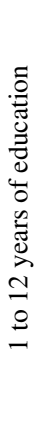 } & 95 & - & - & - & - & - & - & - & - & - & - & - & - & - \\
\hline & 90 & - & - & - & - & - & - & - & - & - & - & - & - & - \\
\hline & 85 & - & - & - & - & - & - & - & - & - & - & 0.3 & 0.6 & 1.0 \\
\hline & 80 & - & - & - & - & - & - & 0.1 & 0.4 & 0.8 & 1.2 & 1.6 & 1.9 & 2.3 \\
\hline & 70 & - & 0.2 & 0.6 & 1.0 & 1.4 & 1.8 & 2.1 & 2.5 & 2.9 & 3.3 & 3.6 & 4.0 & 4.4 \\
\hline & 60 & 1.6 & 2.0 & 2.4 & 2.8 & 3.1 & 3.5 & 3.9 & 4.3 & 4.6 & 5.0 & 5.4 & 5.8 & 6.2 \\
\hline & 50 & 3.3 & 3.6 & 4.0 & 4.4 & 4.8 & 5.1 & 5.5 & 5.9 & 6.3 & 6.7 & 7.0 & 7.4 & 7.8 \\
\hline & 40 & 4.9 & 5.3 & 5.6 & 6.0 & 6.4 & 6.8 & 7.1 & 7.5 & 7.9 & 8.3 & 8.7 & 9.0 & 9.4 \\
\hline & 30 & 6.6 & 7.0 & 7.4 & 7.8 & 8.1 & 8.5 & 8.9 & 9.3 & 9.7 & 10.0 & 10.4 & 10.8 & 11.2 \\
\hline & 20 & 8.7 & 9.1 & 9.5 & 9.9 & 10.2 & 10.6 & 11.0 & 11.4 & 11.7 & 12.1 & 12.5 & 12.9 & 13.2 \\
\hline & 15 & 10.0 & 10.4 & 10.8 & 11.2 & 11.5 & 11.9 & 12.3 & 12.7 & 13.0 & 13.4 & 13.8 & 14.2 & 14.6 \\
\hline & 10 & 11.6 & 12.0 & 12.3 & 12.7 & 13.1 & 13.5 & 13.8 & 14.2 & 14.6 & 15.0 & 15.4 & 15.7 & 16.1 \\
\hline & 5 & 13.9 & 14.3 & 14.7 & 15.1 & 15.4 & 15.8 & 16.2 & 16.6 & 16.9 & 17.3 & 17.7 & 18.1 & 18.5 \\
\hline
\end{tabular}

Table A16

Normative data for the M-WCST Perseveration errors stratified by age and education levels for EL SALVADOR

\begin{tabular}{|c|c|c|c|c|c|c|c|c|c|c|c|c|c|c|}
\hline & \multirow[b]{2}{*}{ Percentile } & \multicolumn{13}{|c|}{ Age (Years) } \\
\hline & & $18-22$ & $23-27$ & $28-32$ & $33-37$ & $38-42$ & $43-47$ & $48-52$ & $53-57$ & $58-62$ & $63-67$ & $68-72$ & $73-77$ & $>77$ \\
\hline \multirow{13}{*}{ 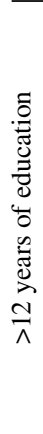 } & 95 & - & - & - & - & - & - & - & - & - & - & - & - & - \\
\hline & 90 & - & - & - & - & - & - & - & - & - & - & - & - & - \\
\hline & 85 & - & - & - & - & - & - & - & - & - & - & - & - & - \\
\hline & 80 & - & - & - & - & - & - & - & - & - & - & - & - & - \\
\hline & 70 & - & - & - & - & - & - & - & - & 0.2 & 0.5 & 0.9 & 1.2 & 1.5 \\
\hline & 60 & - & - & - & 0.3 & 0.6 & 0.9 & 1.2 & 1.5 & 1.9 & 2.2 & 2.5 & 2.8 & 3.1 \\
\hline & 50 & 0.9 & 1.2 & 1.5 & 1.8 & 2.1 & 2.4 & 2.7 & 3.0 & 3.3 & 3.7 & 4.0 & 4.3 & 4.6 \\
\hline & 40 & 2.4 & 2.7 & 3.0 & 3.3 & 3.6 & 3.9 & 4.2 & 4.5 & 4.8 & 5.1 & 5.5 & 5.8 & 6.1 \\
\hline & 30 & 4.0 & 4.3 & 4.6 & 4.9 & 5.2 & 5.5 & 5.8 & 6.1 & 6.4 & 6.8 & 7.1 & 7.4 & 7.7 \\
\hline & 20 & 5.9 & 6.2 & 6.5 & 6.8 & 7.1 & 7.4 & 7.7 & 8.0 & 8.4 & 8.7 & 9.0 & 9.3 & 9.6 \\
\hline & 15 & 7.1 & 7.4 & 7.7 & 8.0 & 8.3 & 8.6 & 8.9 & 9.2 & 9.6 & 9.9 & 10.2 & 10.5 & 10.8 \\
\hline & 10 & 8.5 & 8.8 & 9.1 & 9.4 & 9.7 & 10.1 & 10.4 & 10.7 & 11.0 & 11.3 & 11.6 & 11.9 & 12.2 \\
\hline & 5 & 10.7 & 11.0 & 11.3 & 11.6 & 11.9 & 12.2 & 12.5 & 12.8 & 13.1 & 13.4 & 13.8 & 14.1 & 14.4 \\
\hline \multirow{13}{*}{ 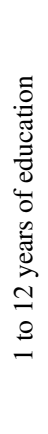 } & 95 & - & - & - & - & - & - & - & - & - & - & - & - & - \\
\hline & 90 & - & - & - & - & - & - & 0.1 & 0.4 & 0.7 & 1.0 & 1.4 & 1.7 & 2.0 \\
\hline & 85 & - & - & 0.3 & 0.6 & 0.9 & 1.2 & 1.5 & 1.9 & 2.2 & 2.5 & 2.8 & 3.1 & 3.4 \\
\hline & 80 & 0.9 & 1.2 & 1.5 & 1.8 & 2.1 & 2.4 & 2.7 & 3.1 & 3.4 & 3.7 & 4.0 & 4.3 & 4.6 \\
\hline & 70 & 2.8 & 3.1 & 3.4 & 3.7 & 4.0 & 4.3 & 4.7 & 5.0 & 5.3 & 5.6 & 5.9 & 6.2 & 6.5 \\
\hline & 60 & 4.4 & 4.7 & 5.0 & 5.3 & 5.6 & 6.0 & 6.3 & 6.6 & 6.9 & 7.2 & 7.5 & 7.8 & 8.1 \\
\hline & 50 & 5.9 & 6.2 & 6.5 & 6.8 & 7.1 & 7.4 & 7.8 & 8.1 & 8.4 & 8.7 & 9.0 & 9.3 & 9.6 \\
\hline & 40 & 7.4 & 7.7 & 8.0 & 8.3 & 8.6 & 8.9 & 9.2 & 9.6 & 9.9 & 10.2 & 10.5 & 10.8 & 11.1 \\
\hline & 30 & 9.0 & 9.3 & 9.6 & 9.9 & 10.2 & 10.5 & 10.9 & 11.2 & 11.5 & 11.8 & 12.1 & 12.4 & 12.7 \\
\hline & 20 & 10.9 & 11.2 & 11.5 & 11.8 & 12.2 & 12.5 & 12.8 & 13.1 & 13.4 & 13.7 & 14.0 & 14.3 & 14.6 \\
\hline & 15 & 12.1 & 12.4 & 12.7 & 13.0 & 13.3 & 13.7 & 14.0 & 14.3 & 14.6 & 14.9 & 15.2 & 15.5 & 15.8 \\
\hline & 10 & 13.5 & 13.8 & 14.2 & 14.5 & 14.8 & 15.1 & 15.4 & 15.7 & 16.0 & 16.3 & 16.6 & 16.9 & 17.3 \\
\hline & 5 & 15.7 & 16.0 & 16.3 & 16.6 & 16.9 & 17.2 & 17.5 & 17.9 & 18.2 & 18.5 & 18.8 & 19.1 & 19.4 \\
\hline
\end{tabular}


Table A17

Normative data for the M-WCST Perseveration errors stratified by education levels for GUATEMALA

\begin{tabular}{lcc}
\hline Percentile & 1 to 12 years of education & $>12$ years of education \\
\hline 95 & - & - \\
90 & - & - \\
85 & - & - \\
80 & 0.7 & - \\
70 & 3.0 & - \\
60 & 5.0 & 1.8 \\
50 & 6.8 & 3.6 \\
40 & 8.7 & 5.4 \\
30 & 10.7 & 7.4 \\
20 & 13.0 & 9.8 \\
15 & 14.5 & 11.2 \\
10 & 16.3 & 13.0 \\
5 & 18.9 & 15.7 \\
\hline
\end{tabular}

Table A18

Normative data for the M-WCST Perseveration errors stratified by education levels for HONDURAS

\begin{tabular}{lcc}
\hline Percentile & 1 to 12 years of education & $>12$ years of education \\
\hline 95 & - & - \\
90 & - & - \\
85 & 1.2 & - \\
80 & 2.5 & - \\
70 & 4.5 & 1.9 \\
60 & 6.2 & 3.6 \\
50 & 7.8 & 5.2 \\
40 & 9.3 & 6.7 \\
30 & 11.0 & 8.4 \\
20 & 13.0 & 10.4 \\
15 & 14.3 & 11.7 \\
10 & 15.8 & 13.2 \\
5 & 18.0 & 15.4 \\
\hline
\end{tabular}


Table A19

Normative data for the M-WCST Perseveration errors stratified by age and education levels for MEXICO

\begin{tabular}{|c|c|c|c|c|c|c|c|c|c|c|c|c|c|c|}
\hline & \multirow[b]{2}{*}{ Percentile } & \multicolumn{13}{|c|}{ Age (Years) } \\
\hline & & $18-22$ & $23-27$ & $28-32$ & $33-37$ & $38-42$ & $43-47$ & $48-52$ & $53-57$ & $58-62$ & $63-67$ & $68-72$ & $73-77$ & $>77$ \\
\hline \multirow{13}{*}{ 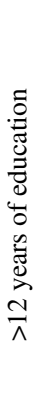 } & 95 & - & - & - & - & - & - & - & - & - & - & - & - & $\overline{-}$ \\
\hline & 90 & - & - & - & - & - & - & - & - & - & - & - & - & - \\
\hline & 85 & - & - & - & - & - & - & - & - & - & - & - & - & - \\
\hline & 80 & - & - & - & - & - & - & - & - & - & - & - & 0.3 & 0.8 \\
\hline & 70 & - & - & - & - & - & - & - & 0.3 & 0.8 & 1.3 & 1.8 & 2.3 & 2.9 \\
\hline & 60 & - & - & - & - & 0.4 & 0.9 & 1.5 & 2.0 & 2.5 & 3.0 & 3.5 & 4.0 & 4.6 \\
\hline & 50 & - & 0.4 & 1.0 & 1.5 & 2.0 & 2.5 & 3.0 & 3.5 & 4.1 & 4.6 & 5.1 & 5.6 & 6.1 \\
\hline & 40 & 1.5 & 2.0 & 2.5 & 3.0 & 3.6 & 4.1 & 4.6 & 5.1 & 5.6 & 6.1 & 6.7 & 7.2 & 7.7 \\
\hline & 30 & 3.2 & 3.7 & 4.2 & 4.7 & 5.3 & 5.8 & 6.3 & 6.8 & 7.3 & 7.8 & 8.4 & 8.9 & 9.4 \\
\hline & 20 & 5.2 & 5.7 & 6.2 & 6.8 & 7.3 & 7.8 & 8.3 & 8.8 & 9.3 & 9.9 & 10.4 & 10.9 & 11.4 \\
\hline & 15 & 6.5 & 7.0 & 7.5 & 8.0 & 8.5 & 9.0 & 9.6 & 10.1 & 10.6 & 11.1 & 11.6 & 12.1 & 12.7 \\
\hline & 10 & 8.0 & 8.5 & 9.0 & 9.5 & 10.0 & 10.5 & 11.1 & 11.6 & 12.1 & 12.6 & 13.1 & 13.6 & 14.2 \\
\hline & 5 & 10.2 & 10.7 & 11.3 & 11.8 & 12.3 & 12.8 & 13.3 & 13.8 & 14.4 & 14.9 & 15.4 & 15.9 & 16.4 \\
\hline \multirow{13}{*}{ 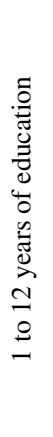 } & 95 & - & - & - & - & - & - & - & - & - & - & - & - & - \\
\hline & 90 & - & - & - & - & - & - & - & - & - & - & - & - & 0.1 \\
\hline & 85 & - & - & - & - & - & - & - & - & - & 0.1 & 0.6 & 1.1 & 1.6 \\
\hline & 80 & - & - & - & - & - & - & - & 0.3 & 0.8 & 1.3 & 1.9 & 2.4 & 2.9 \\
\hline & 70 & - & - & - & 0.3 & 0.8 & 1.3 & 1.8 & 2.3 & 2.8 & 3.4 & 3.9 & 4.4 & 4.9 \\
\hline & 60 & 0.4 & 0.9 & 1.4 & 2.0 & 2.5 & 3.0 & 3.5 & 4.0 & 4.5 & 5.1 & 5.6 & 6.1 & 6.6 \\
\hline & 50 & 2.0 & 2.5 & 3.0 & 3.5 & 4.0 & 4.6 & 5.1 & 5.6 & 6.1 & 6.6 & 7.1 & 7.7 & 8.2 \\
\hline & 40 & 3.5 & 4.1 & 4.6 & 5.1 & 5.6 & 6.1 & 6.6 & 7.2 & 7.7 & 8.2 & 8.7 & 9.2 & 9.7 \\
\hline & 30 & 5.2 & 5.8 & 6.3 & 6.8 & 7.3 & 7.8 & 8.3 & 8.9 & 9.4 & 9.9 & 10.4 & 10.9 & 11.4 \\
\hline & 20 & 7.3 & 7.8 & 8.3 & 8.8 & 9.3 & 9.8 & 10.3 & 10.9 & 11.4 & 11.9 & 12.4 & 12.9 & 13.4 \\
\hline & 15 & 8.5 & 9.0 & 9.5 & 10.1 & 10.6 & 11.1 & 11.6 & 12.1 & 12.6 & 13.2 & 13.7 & 14.2 & 14.7 \\
\hline & 10 & 10.0 & 10.5 & 11.0 & 11.6 & 12.1 & 12.6 & 13.1 & 13.6 & 14.1 & 14.7 & 15.2 & 15.7 & 16.2 \\
\hline & 5 & 12.3 & 12.8 & 13.3 & 13.8 & 14.3 & 14.9 & 15.4 & 15.9 & 16.4 & 16.9 & 17.4 & 18.0 & 18.5 \\
\hline
\end{tabular}

Table A20

Normative data for the M-WCST Perseveration errors stratified by age and education levels for PARAGUAY

\begin{tabular}{|c|c|c|c|c|c|c|c|c|c|c|c|c|c|c|}
\hline & \multirow[b]{2}{*}{ Percentile } & \multicolumn{13}{|c|}{ Age (Years) } \\
\hline & & $18-22$ & $23-27$ & $28-32$ & $33-37$ & $38-42$ & $43-47$ & $48-52$ & $53-57$ & $58-62$ & $63-67$ & $68-72$ & $73-77$ & $>77$ \\
\hline \multirow{13}{*}{ 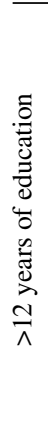 } & 95 & - & - & - & - & - & - & - & 0.3 & 0.6 & 0.9 & 1.2 & 1.6 & 1.9 \\
\hline & 90 & - & - & - & - & 0.1 & 0.5 & 0.8 & 1.1 & 1.5 & 1.8 & 2.1 & 2.5 & 2.8 \\
\hline & 85 & - & - & 0.1 & 0.4 & 0.7 & 1.1 & 1.4 & 1.7 & 2.1 & 2.4 & 2.7 & 3.1 & 3.4 \\
\hline & 80 & - & 0.2 & 0.6 & 0.9 & 1.2 & 1.6 & 1.9 & 2.2 & 2.6 & 2.9 & 3.2 & 3.6 & 3.9 \\
\hline & 70 & 0.7 & 1.0 & 1.4 & 1.7 & 2.0 & 2.4 & 2.7 & 3.0 & 3.3 & 3.7 & 4.0 & 4.3 & 4.7 \\
\hline & 60 & 1.4 & 1.7 & 2.0 & 2.4 & 2.7 & 3.0 & 3.3 & 3.7 & 4.0 & 4.3 & 4.7 & 5.0 & 5.3 \\
\hline & 50 & 2.0 & 2.3 & 2.6 & 3.0 & 3.3 & 3.6 & 4.0 & 4.3 & 4.6 & 5.0 & 5.3 & 5.6 & 6.0 \\
\hline & 40 & 2.6 & 2.9 & 3.3 & 3.6 & 3.9 & 4.3 & 4.6 & 4.9 & 5.2 & 5.6 & 5.9 & 6.2 & 6.6 \\
\hline & 30 & 3.3 & 3.6 & 3.9 & 4.3 & 4.6 & 4.9 & 5.3 & 5.6 & 5.9 & 6.2 & 6.6 & 6.9 & 7.2 \\
\hline & 20 & 4.0 & 4.4 & 4.7 & 5.0 & 5.4 & 5.7 & 6.0 & 6.4 & 6.7 & 7.0 & 7.4 & 7.7 & 8.0 \\
\hline & 15 & 4.5 & 4.9 & 5.2 & 5.5 & 5.9 & 6.2 & 6.5 & 6.9 & 7.2 & 7.5 & 7.9 & 8.2 & 8.5 \\
\hline & 10 & 5.1 & 5.5 & 5.8 & 6.1 & 6.5 & 6.8 & 7.1 & 7.5 & 7.8 & 8.1 & 8.5 & 8.8 & 9.1 \\
\hline & 5 & 6.0 & 6.4 & 6.7 & 7.0 & 7.4 & 7.7 & 8.0 & 8.3 & 8.7 & 9.0 & 9.3 & 9.7 & 10.0 \\
\hline \multirow{13}{*}{ 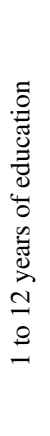 } & 95 & 0.6 & 1.0 & 1.3 & 1.6 & 2.0 & 2.3 & 2.6 & 3.0 & 3.3 & 3.6 & 4.0 & 4.3 & 4.6 \\
\hline & 90 & 1.5 & 1.9 & 2.2 & 2.5 & 2.8 & 3.2 & 3.5 & 3.8 & 4.2 & 4.5 & 4.8 & 5.2 & 5.5 \\
\hline & 85 & 2.1 & 2.4 & 2.8 & 3.1 & 3.4 & 3.8 & 4.1 & 4.4 & 4.8 & 5.1 & 5.4 & 5.8 & 6.1 \\
\hline & 80 & 2.6 & 2.9 & 3.3 & 3.6 & 3.9 & 4.3 & 4.6 & 4.9 & 5.3 & 5.6 & 5.9 & 6.3 & 6.6 \\
\hline & 70 & 3.4 & 3.7 & 4.1 & 4.4 & 4.7 & 5.1 & 5.4 & 5.7 & 6.1 & 6.4 & 6.7 & 7.1 & 7.4 \\
\hline & 60 & 4.1 & 4.4 & 4.7 & 5.1 & 5.4 & 5.7 & 6.1 & 6.4 & 6.7 & 7.1 & 7.4 & 7.7 & 8.1 \\
\hline & 50 & 4.7 & 5.0 & 5.3 & 5.7 & 6.0 & 6.3 & 6.7 & 7.0 & 7.3 & 7.7 & 8.0 & 8.3 & 8.7 \\
\hline & 40 & 5.3 & 5.6 & 6.0 & 6.3 & 6.6 & 7.0 & 7.3 & 7.6 & 8.0 & 8.3 & 8.6 & 9.0 & 9.3 \\
\hline & 30 & 6.0 & 6.3 & 6.6 & 7.0 & 7.3 & 7.6 & 8.0 & 8.3 & 8.6 & 9.0 & 9.3 & 9.6 & 10.0 \\
\hline & 20 & 6.8 & 7.1 & 7.4 & 7.8 & 8.1 & 8.4 & 8.7 & 9.1 & 9.4 & 9.7 & 10.1 & 10.4 & 10.7 \\
\hline & 15 & 7.2 & 7.6 & 7.9 & 8.2 & 8.6 & 8.9 & 9.2 & 9.6 & 9.9 & 10.2 & 10.6 & 10.9 & 11.2 \\
\hline & 10 & 7.8 & 8.2 & 8.5 & 8.8 & 9.2 & 9.5 & 9.8 & 10.2 & 10.5 & 10.8 & 11.2 & 11.5 & 11.8 \\
\hline & 5 & 8.7 & 9.1 & 9.4 & 9.7 & 10.1 & 10.4 & 10.7 & 11.1 & 11.4 & 11.7 & 12.1 & 12.4 & 12.7 \\
\hline
\end{tabular}


Table A21

Normative data for the M-WCST Perseveration errors stratified by age and education levels for PERU

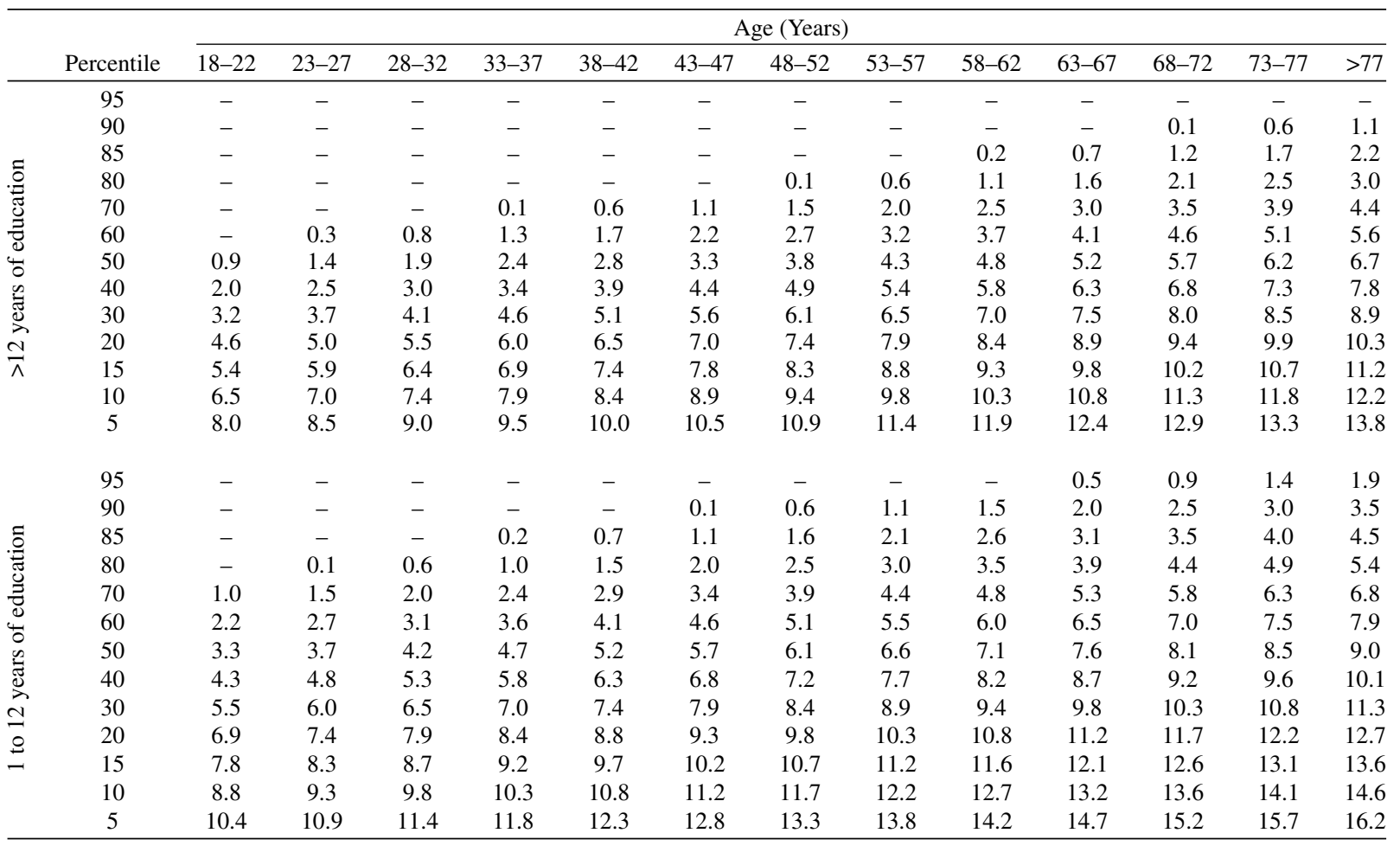

Table A22

Normative data for the M-WCST Perseveration errors stratified by age and education levels for PUERTO RICO

\begin{tabular}{|c|c|c|c|c|c|c|c|c|c|c|c|c|c|c|}
\hline & \multirow[b]{2}{*}{ Percentile } & \multicolumn{13}{|c|}{ Age (Years) } \\
\hline & & $18-22$ & $23-27$ & $28-32$ & $33-37$ & $38-42$ & $43-47$ & $48-52$ & $53-57$ & $58-62$ & $63-67$ & $68-72$ & $73-77$ & $>77$ \\
\hline \multirow{13}{*}{ 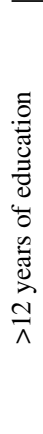 } & 95 & - & - & - & - & - & - & - & - & - & - & - & - & - \\
\hline & 90 & - & - & - & - & - & - & - & - & - & - & - & - & - \\
\hline & 85 & - & - & - & - & - & - & - & - & - & - & - & - & - \\
\hline & 80 & - & - & - & - & - & - & - & - & - & - & - & - & - \\
\hline & 70 & - & - & - & - & - & - & - & - & - & 0.4 & 0.8 & 1.3 & 1.8 \\
\hline & 60 & - & - & - & - & - & 0.2 & 0.7 & 1.2 & 1.7 & 2.1 & 2.6 & 3.1 & 3.6 \\
\hline & 50 & - & - & 0.5 & 0.9 & 1.4 & 1.9 & 2.4 & 2.8 & 3.3 & 3.8 & 4.3 & 4.7 & 5.2 \\
\hline & 40 & 1.2 & 1.6 & 2.1 & 2.6 & 3.1 & 3.5 & 4.0 & 4.5 & 5.0 & 5.4 & 5.9 & 6.4 & 6.9 \\
\hline & 30 & 3.0 & 3.4 & 3.9 & 4.4 & 4.9 & 5.3 & 5.8 & 6.3 & 6.8 & 7.2 & 7.7 & 8.2 & 8.7 \\
\hline & 20 & 5.1 & 5.5 & 6.0 & 6.5 & 7.0 & 7.4 & 7.9 & 8.4 & 8.9 & 9.3 & 9.8 & 10.3 & 10.8 \\
\hline & 15 & 6.4 & 6.9 & 7.3 & 7.8 & 8.3 & 8.8 & 9.2 & 9.7 & 10.2 & 10.7 & 11.1 & 11.6 & 12.1 \\
\hline & 10 & 8.0 & 8.5 & 8.9 & 9.4 & 9.9 & 10.4 & 10.8 & 11.3 & 11.8 & 12.3 & 12.7 & 13.2 & 13.7 \\
\hline & 5 & 10.4 & 10.8 & 11.3 & 11.8 & 12.3 & 12.7 & 13.2 & 13.7 & 14.2 & 14.6 & 15.1 & 15.6 & 16.1 \\
\hline \multirow{13}{*}{ 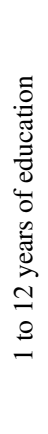 } & 95 & - & - & - & - & - & - & - & - & - & - & - & - & - \\
\hline & 90 & - & - & - & - & - & - & - & - & - & - & - & - & - \\
\hline & 85 & - & - & - & - & - & - & - & - & - & - & - & 0.1 & 0.6 \\
\hline & 80 & - & - & - & - & - & - & - & - & - & 0.5 & 1.0 & 1.4 & 1.9 \\
\hline & 70 & - & - & - & - & 0.2 & 0.7 & 1.2 & 1.7 & 2.1 & 2.6 & 3.1 & 3.6 & 4.0 \\
\hline & 60 & 0.1 & 0.6 & 1.1 & 1.5 & 2.0 & 2.5 & 3.0 & 3.4 & 3.9 & 4.4 & 4.9 & 5.3 & 5.8 \\
\hline & 50 & 1.8 & 2.2 & 2.7 & 3.2 & 3.7 & 4.1 & 4.6 & 5.1 & 5.6 & 6.0 & 6.5 & 7.0 & 7.5 \\
\hline & 40 & 3.4 & 3.9 & 4.4 & 4.8 & 5.3 & 5.8 & 6.3 & 6.7 & 7.2 & 7.7 & 8.2 & 8.6 & 9.1 \\
\hline & 30 & 5.2 & 5.7 & 6.2 & 6.6 & 7.1 & 7.6 & 8.1 & 8.5 & 9.0 & 9.5 & 10.0 & 10.4 & 10.9 \\
\hline & 20 & 7.3 & 7.8 & 8.3 & 8.7 & 9.2 & 9.7 & 10.2 & 10.6 & 11.1 & 11.6 & 12.1 & 12.5 & 13.0 \\
\hline & 15 & 8.6 & 9.1 & 9.6 & 10.1 & 10.5 & 11.0 & 11.5 & 12.0 & 12.4 & 12.9 & 13.4 & 13.9 & 14.3 \\
\hline & 10 & 10.2 & 10.7 & 11.2 & 11.7 & 12.1 & 12.6 & 13.1 & 13.6 & 14.0 & 14.5 & 15.0 & 15.5 & 15.9 \\
\hline & 5 & 12.6 & 13.1 & 13.6 & 14.0 & 14.5 & 15.0 & 15.5 & 15.9 & 16.4 & 16.9 & 17.4 & 17.8 & 18.3 \\
\hline
\end{tabular}


Table A23

Normative data for the M-WCST total errors stratified by age and education levels for ARGENTINA

\begin{tabular}{|c|c|c|c|c|c|c|c|c|c|c|c|c|c|c|}
\hline & \multirow[b]{2}{*}{ Percentile } & \multicolumn{13}{|c|}{ Age (Years) } \\
\hline & & $18-22$ & $23-27$ & $28-32$ & $33-37$ & $38-42$ & $43-47$ & $48-52$ & $53-57$ & $58-62$ & $63-67$ & $68-72$ & $73-77$ & $>77$ \\
\hline \multirow{13}{*}{ 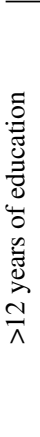 } & 95 & - & - & - & - & - & - & - & - & - & - & - & - & - \\
\hline & 90 & - & - & - & - & - & - & - & - & - & - & - & - & - \\
\hline & 85 & - & - & - & - & - & - & - & - & - & 0.2 & 0.5 & 0.7 & 1.0 \\
\hline & 80 & - & - & - & - & - & 0.3 & 0.6 & 0.8 & 1.1 & 1.3 & 1.6 & 1.9 & 2.1 \\
\hline & 70 & 0.8 & 1.1 & 1.3 & 1.6 & 1.8 & 2.1 & 2.4 & 2.6 & 2.9 & 3.1 & 3.4 & 3.7 & 3.9 \\
\hline & 60 & 2.3 & 2.6 & 2.8 & 3.1 & 3.4 & 3.6 & 3.9 & 4.1 & 4.4 & 4.7 & 4.9 & 5.2 & 5.4 \\
\hline & 50 & 3.7 & 4.0 & 4.2 & 4.5 & 4.8 & 5.0 & 5.3 & 5.5 & 5.8 & 6.1 & 6.3 & 6.6 & 6.8 \\
\hline & 40 & 5.1 & 5.4 & 5.6 & 5.9 & 6.2 & 6.4 & 6.7 & 7.0 & 7.2 & 7.5 & 7.7 & 8.0 & 8.3 \\
\hline & 30 & 6.6 & 6.9 & 7.2 & 7.4 & 7.7 & 8.0 & 8.2 & 8.5 & 8.7 & 9.0 & 9.3 & 9.5 & 9.8 \\
\hline & 20 & 8.4 & 8.7 & 9.0 & 9.2 & 9.5 & 9.8 & 10.0 & 10.3 & 10.5 & 10.8 & 11.1 & 11.3 & 11.6 \\
\hline & 15 & 9.6 & 9.8 & 10.1 & 10.4 & 10.6 & 10.9 & 11.1 & 11.4 & 11.7 & 11.9 & 12.2 & 12.4 & 12.7 \\
\hline & 10 & 10.9 & 11.2 & 11.4 & 11.7 & 12.0 & 12.2 & 12.5 & 12.8 & 13.0 & 13.3 & 13.5 & 13.8 & 14.1 \\
\hline & 5 & 13.0 & 13.2 & 13.5 & 13.7 & 14.0 & 14.3 & 14.5 & 14.8 & 15.0 & 15.3 & 15.6 & 15.8 & 16.1 \\
\hline \multirow{13}{*}{ 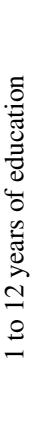 } & 95 & - & - & - & - & - & - & - & 0.3 & 0.6 & 0.8 & 1.1 & 1.4 & 1.6 \\
\hline & 90 & 0.5 & 0.8 & 1.0 & 1.3 & 1.6 & 1.8 & 2.1 & 2.3 & 2.6 & 2.9 & 3.1 & 3.4 & 3.6 \\
\hline & 85 & 1.9 & 2.1 & 2.4 & 2.6 & 2.9 & 3.2 & 3.4 & 3.7 & 3.9 & 4.2 & 4.5 & 4.7 & 5.0 \\
\hline & 80 & 3.0 & 3.2 & 3.5 & 3.8 & 4.0 & 4.3 & 4.6 & 4.8 & 5.1 & 5.3 & 5.6 & 5.9 & 6.1 \\
\hline & 70 & 4.8 & 5.1 & 5.3 & 5.6 & 5.8 & 6.1 & 6.4 & 6.6 & 6.9 & 7.1 & 7.4 & 7.7 & 7.9 \\
\hline & 60 & 6.3 & 6.6 & 6.8 & 7.1 & 7.4 & 7.6 & 7.9 & 8.1 & 8.4 & 8.7 & 8.9 & 9.2 & 9.4 \\
\hline & 50 & 7.7 & 8.0 & 8.2 & 8.5 & 8.8 & 9.0 & 9.3 & 9.5 & 9.8 & 10.1 & 10.3 & 10.6 & 10.8 \\
\hline & 40 & 9.1 & 9.4 & 9.6 & 9.9 & 10.2 & 10.4 & 10.7 & 11.0 & 11.2 & 11.5 & 11.7 & 12.0 & 12.3 \\
\hline & 30 & 10.6 & 10.9 & 11.2 & 11.4 & 11.7 & 11.9 & 12.2 & 12.5 & 12.7 & 13.0 & 13.3 & 13.5 & 13.8 \\
\hline & 20 & 12.4 & 12.7 & 13.0 & 13.2 & 13.5 & 13.8 & 14.0 & 14.3 & 14.5 & 14.8 & 15.1 & 15.3 & 15.6 \\
\hline & 15 & 13.6 & 13.8 & 14.1 & 14.4 & 14.6 & 14.9 & 15.1 & 15.4 & 15.7 & 15.9 & 16.2 & 16.4 & 16.7 \\
\hline & 10 & 14.9 & 15.2 & 15.4 & 15.7 & 16.0 & 16.2 & 16.5 & 16.8 & 17.0 & 17.3 & 17.5 & 17.8 & 18.1 \\
\hline & 5 & 17.0 & 17.2 & 17.5 & 17.7 & 18.0 & 18.3 & 18.5 & 18.8 & 19.0 & 19.3 & 19.6 & 19.8 & 20.1 \\
\hline
\end{tabular}

Table A24

Normative data for the M-WCST total errors stratified by age for BOLIVIA

\begin{tabular}{|c|c|c|c|c|c|c|c|c|c|c|c|c|c|}
\hline \multirow[b]{2}{*}{ Percentile } & \multicolumn{13}{|c|}{ Age (Years) } \\
\hline & $18-22$ & $23-27$ & $28-32$ & $33-37$ & $38-42$ & $43-47$ & $48-52$ & $53-57$ & $58-62$ & $63-67$ & $68-72$ & $73-77$ & $>77$ \\
\hline$\overline{95}$ & - & - & - & - & - & - & - & - & - & - & - & - & - \\
\hline 90 & - & - & - & - & - & - & - & - & - & - & - & 0.4 & 1.0 \\
\hline 85 & - & - & - & - & - & - & - & - & 0.4 & 1.0 & 1.5 & 2.1 & 2.6 \\
\hline 80 & - & - & - & - & - & 0.2 & 0.7 & 1.2 & 1.8 & 2.3 & 2.9 & 3.4 & 3.9 \\
\hline 70 & - & 0.2 & 0.7 & 1.2 & 1.8 & 2.3 & 2.9 & 3.4 & 3.9 & 4.5 & 5.0 & 5.6 & 6.1 \\
\hline 60 & 1.4 & 2.0 & 2.5 & 3.1 & 3.6 & 4.1 & 4.7 & 5.2 & 5.8 & 6.3 & 6.8 & 7.4 & 7.9 \\
\hline 50 & 3.1 & 3.7 & 4.2 & 4.8 & 5.3 & 5.8 & 6.4 & 6.9 & 7.5 & 8.0 & 8.5 & 9.1 & 9.6 \\
\hline 40 & 4.8 & 5.4 & 5.9 & 6.4 & 7.0 & 7.5 & 8.1 & 8.6 & 9.1 & 9.7 & 10.2 & 10.8 & 11.3 \\
\hline 30 & 6.6 & 7.2 & 7.7 & 8.3 & 8.8 & 9.3 & 9.9 & 10.4 & 11.0 & 11.5 & 12.0 & 12.6 & 13.1 \\
\hline 20 & 8.8 & 9.3 & 9.9 & 10.4 & 11.0 & 11.5 & 12.0 & 12.6 & 13.1 & 13.7 & 14.2 & 14.7 & 15.3 \\
\hline 15 & 10.1 & 10.7 & 11.2 & 11.8 & 12.3 & 12.8 & 13.4 & 13.9 & 14.5 & 15.0 & 15.5 & 16.1 & 16.6 \\
\hline 10 & 11.8 & 12.3 & 12.8 & 13.4 & 13.9 & 14.5 & 15.0 & 15.5 & 16.1 & 16.6 & 17.2 & 17.7 & 18.2 \\
\hline 5 & 14.2 & 14.7 & 15.3 & 15.8 & 16.4 & 16.9 & 17.4 & 18.0 & 18.5 & 19.1 & 19.6 & 20.1 & 20.7 \\
\hline
\end{tabular}


Table A25

Normative data for the M-WCST total errors stratified by age for CHILE

\begin{tabular}{|c|c|c|c|c|c|c|c|c|c|c|c|c|c|}
\hline \multirow[b]{2}{*}{ Percentile } & \multicolumn{13}{|c|}{ Age (Years) } \\
\hline & $18-22$ & $23-27$ & $28-32$ & $33-37$ & $38-42$ & $43-47$ & $48-52$ & $53-57$ & $58-62$ & $63-67$ & $68-72$ & $73-77$ & $>77$ \\
\hline 95 & - & - & - & - & - & - & - & - & - & - & - & - & - \\
\hline 90 & - & - & - & - & - & - & - & - & - & - & - & - & - \\
\hline 85 & - & - & - & - & - & - & - & - & - & - & - & - & - \\
\hline 80 & - & - & - & - & - & - & - & - & - & - & - & - & - \\
\hline 70 & - & - & - & - & - & - & - & 0.1 & 0.3 & 0.5 & 0.7 & 0.9 & 1.1 \\
\hline 60 & 0.1 & 0.3 & 0.4 & 0.6 & 0.8 & 1.0 & 1.2 & 1.4 & 1.6 & 1.8 & 1.9 & 2.1 & 2.3 \\
\hline 50 & 1.2 & 1.4 & 1.6 & 1.8 & 2.0 & 2.1 & 2.3 & 2.5 & 2.7 & 2.9 & 3.1 & 3.3 & 3.5 \\
\hline 40 & 2.3 & 2.5 & 2.7 & 2.9 & 3.1 & 3.3 & 3.5 & 3.7 & 3.8 & 4.0 & 4.2 & 4.4 & 4.6 \\
\hline 30 & 3.6 & 3.8 & 3.9 & 4.1 & 4.3 & 4.5 & 4.7 & 4.9 & 5.1 & 5.3 & 5.4 & 5.6 & 5.8 \\
\hline 20 & 5.0 & 5.2 & 5.4 & 5.6 & 5.8 & 6.0 & 6.1 & 6.3 & 6.5 & 6.7 & 6.9 & 7.1 & 7.3 \\
\hline 15 & 5.9 & 6.1 & 6.3 & 6.5 & 6.7 & 6.9 & 7.1 & 7.2 & 7.4 & 7.6 & 7.8 & 8.0 & 8.2 \\
\hline 10 & 7.0 & 7.2 & 7.4 & 7.6 & 7.8 & 8.0 & 8.1 & 8.3 & 8.5 & 8.7 & 8.9 & 9.1 & 9.3 \\
\hline 5 & 8.7 & 8.8 & 9.0 & 9.2 & 9.4 & 9.6 & 9.8 & 10.0 & 10.2 & 10.3 & 10.5 & 10.7 & 10.9 \\
\hline
\end{tabular}

Table A26

Normative data for the M-WCST total errors stratified by age and education levels for CUBA

\begin{tabular}{|c|c|c|c|c|c|c|c|c|c|c|c|c|c|c|}
\hline & \multirow[b]{2}{*}{ Percentile } & \multicolumn{13}{|c|}{ Age (Years) } \\
\hline & & $18-22$ & $23-27$ & $28-32$ & $33-37$ & $38-42$ & $43-47$ & $48-52$ & $53-57$ & $58-62$ & $63-67$ & $68-72$ & $73-77$ & $>77$ \\
\hline \multirow{13}{*}{ 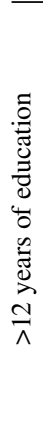 } & 95 & - & - & - & - & - & - & - & - & - & - & - & - & - \\
\hline & 90 & - & - & - & - & - & - & - & - & - & - & 0.2 & 0.8 & 1.5 \\
\hline & 85 & - & - & - & - & - & - & - & 0.4 & 1.1 & 1.7 & 2.4 & 3.1 & 3.7 \\
\hline & 80 & - & - & - & - & 0.3 & 0.9 & 1.6 & 2.3 & 2.9 & 3.6 & 4.2 & 4.9 & 5.6 \\
\hline & 70 & 0.6 & 1.2 & 1.9 & 2.6 & 3.2 & 3.9 & 4.5 & 5.2 & 5.9 & 6.5 & 7.2 & 7.9 & 8.5 \\
\hline & 60 & 3.1 & 3.7 & 4.4 & 5.1 & 5.7 & 6.4 & 7.0 & 7.7 & 8.4 & 9.0 & 9.7 & 10.3 & 11.0 \\
\hline & 50 & 5.4 & 6.0 & 6.7 & 7.4 & 8.0 & 8.7 & 9.3 & 10.0 & 10.7 & 11.3 & 12.0 & 12.7 & 13.3 \\
\hline & 40 & 7.7 & 8.3 & 9.0 & 9.7 & 10.3 & 11.0 & 11.7 & 12.3 & 13.0 & 13.6 & 14.3 & 15.0 & 15.6 \\
\hline & 30 & 10.2 & 10.8 & 11.5 & 12.2 & 12.8 & 13.5 & 14.1 & 14.8 & 15.5 & 16.1 & 16.8 & 17.5 & 18.1 \\
\hline & 20 & 13.1 & 13.8 & 14.4 & 15.1 & 15.8 & 16.4 & 17.1 & 17.8 & 18.4 & 19.1 & 19.7 & 20.4 & 21.1 \\
\hline & 15 & 15.0 & 15.6 & 16.3 & 17.0 & 17.6 & 18.3 & 18.9 & 19.6 & 20.3 & 20.9 & 21.6 & 22.2 & 22.9 \\
\hline & 10 & 17.2 & 17.8 & 18.5 & 19.2 & 19.8 & 20.5 & 21.2 & 21.8 & 22.5 & 23.1 & 23.8 & 24.5 & 25.1 \\
\hline & 5 & 20.5 & 21.2 & 21.8 & 22.5 & 23.1 & 23.8 & 24.5 & 25.1 & 25.8 & 26.5 & 27.1 & 27.8 & 28.4 \\
\hline \multirow{13}{*}{ 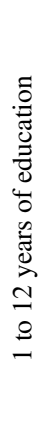 } & 95 & - & - & - & - & - & - & - & - & - & - & 0.5 & 1.2 & 1.8 \\
\hline & 90 & - & - & - & - & - & 0.5 & 1.2 & 1.8 & 2.5 & 3.1 & 3.8 & 4.5 & 5.1 \\
\hline & 85 & - & 0.1 & 0.7 & 1.4 & 2.1 & 2.7 & 3.4 & 4.0 & 4.7 & 5.4 & 6.0 & 6.7 & 7.3 \\
\hline & 80 & 1.2 & 1.9 & 2.6 & 3.2 & 3.9 & 4.6 & 5.2 & 5.9 & 6.5 & 7.2 & 7.9 & 8.5 & 9.2 \\
\hline & 70 & 4.2 & 4.9 & 5.5 & 6.2 & 6.8 & 7.5 & 8.2 & 8.8 & 9.5 & 10.2 & 10.8 & 11.5 & 12.1 \\
\hline & 60 & 6.7 & 7.4 & 8.0 & 8.7 & 9.3 & 10.0 & 10.7 & 11.3 & 12.0 & 12.6 & 13.3 & 14.0 & 14.6 \\
\hline & 50 & 9.0 & 9.7 & 10.3 & 11.0 & 11.6 & 12.3 & 13.0 & 13.6 & 14.3 & 15.0 & 15.6 & 16.3 & 16.9 \\
\hline & 40 & 11.3 & 12.0 & 12.6 & 13.3 & 14.0 & 14.6 & 15.3 & 15.9 & 16.6 & 17.3 & 17.9 & 18.6 & 19.2 \\
\hline & 30 & 13.8 & 14.5 & 15.1 & 15.8 & 16.4 & 17.1 & 17.8 & 18.4 & 19.1 & 19.8 & 20.4 & 21.1 & 21.7 \\
\hline & 20 & 16.7 & 17.4 & 18.1 & 18.7 & 19.4 & 20.1 & 20.7 & 21.4 & 22.0 & 22.7 & 23.4 & 24.0 & 24.7 \\
\hline & 15 & 18.6 & 19.3 & 19.9 & 20.6 & 21.2 & 21.9 & 22.6 & 23.2 & 23.9 & 24.6 & 25.2 & 25.9 & 26.5 \\
\hline & 10 & 20.8 & 21.5 & 22.1 & 22.8 & 23.5 & 24.1 & 24.8 & 25.4 & 26.1 & 26.8 & 27.4 & 28.1 & 28.8 \\
\hline & 5 & 24.1 & 24.8 & 25.5 & 26.1 & 26.8 & 27.4 & 28.1 & 28.8 & 29.4 & 30.1 & 30.7 & 31.4 & 32.1 \\
\hline
\end{tabular}


Table A27

Normative data for the M-WCST total errors stratified by age and education levels for EL SALVADOR

\begin{tabular}{|c|c|c|c|c|c|c|c|c|c|c|c|c|c|c|}
\hline & \multirow[b]{2}{*}{ Percentile } & \multicolumn{13}{|c|}{ Age (Years) } \\
\hline & & $18-22$ & $23-27$ & $28-32$ & $33-37$ & $38-42$ & $43-47$ & $48-52$ & $53-57$ & $58-62$ & $63-67$ & $68-72$ & $73-77$ & $>77$ \\
\hline \multirow{13}{*}{ 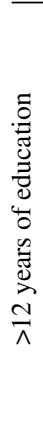 } & 95 & - & - & - & - & - & - & - & - & - & - & - & - & - \\
\hline & 90 & - & - & - & - & - & - & - & - & - & - & - & - & - \\
\hline & 85 & - & - & - & - & - & - & - & - & - & - & - & - & - \\
\hline & 80 & - & - & - & - & - & - & - & - & - & 0.2 & 0.7 & 1.2 & 1.7 \\
\hline & 70 & - & - & - & 0.4 & 0.9 & 1.4 & 1.9 & 2.4 & 2.9 & 3.4 & 3.9 & 4.4 & 4.9 \\
\hline & 60 & 1.7 & 2.2 & 2.7 & 3.2 & 3.7 & 4.2 & 4.7 & 5.2 & 5.7 & 6.2 & 6.6 & 7.1 & 7.6 \\
\hline & 50 & 4.2 & 4.7 & 5.2 & 5.7 & 6.2 & 6.7 & 7.2 & 7.7 & 8.2 & 8.7 & 9.2 & 9.7 & 10.2 \\
\hline & 40 & 6.7 & 7.2 & 7.7 & 8.2 & 8.7 & 9.2 & 9.7 & 10.2 & 10.7 & 11.2 & 11.7 & 12.2 & 12.7 \\
\hline & 30 & 9.4 & 9.9 & 10.4 & 10.9 & 11.4 & 11.9 & 12.4 & 12.9 & 13.4 & 13.9 & 14.4 & 14.9 & 15.4 \\
\hline & 20 & 12.7 & 13.1 & 13.6 & 14.1 & 14.6 & 15.1 & 15.6 & 16.1 & 16.6 & 17.1 & 17.6 & 18.1 & 18.6 \\
\hline & 15 & 14.7 & 15.2 & 15.7 & 16.2 & 16.7 & 17.2 & 17.7 & 18.1 & 18.6 & 19.1 & 19.6 & 20.1 & 20.6 \\
\hline & 10 & 17.1 & 17.6 & 18.1 & 18.6 & 19.1 & 19.6 & 20.1 & 20.6 & 21.1 & 21.6 & 22.1 & 22.6 & 23.1 \\
\hline & 5 & 20.7 & 21.2 & 21.7 & 22.2 & 22.7 & 23.2 & 23.7 & 24.2 & 24.7 & 25.2 & 25.7 & 26.2 & 26.7 \\
\hline \multirow{13}{*}{ 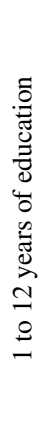 } & 95 & - & - & 0.1 & 0.6 & 1.1 & 1.6 & 2.1 & 2.6 & 3.1 & 3.6 & 4.1 & 4.6 & 5.1 \\
\hline & 90 & 2.7 & 3.2 & 3.7 & 4.2 & 4.7 & 5.2 & 5.7 & 6.2 & 6.7 & 7.2 & 7.7 & 8.2 & 8.7 \\
\hline & 85 & 5.1 & 5.6 & 6.1 & 6.6 & 7.1 & 7.6 & 8.1 & 8.6 & 9.1 & 9.6 & 10.1 & 10.6 & 11.1 \\
\hline & 80 & 7.2 & 7.6 & 8.1 & 8.6 & 9.1 & 9.6 & 10.1 & 10.6 & 11.1 & 11.6 & 12.1 & 12.6 & 13.1 \\
\hline & 70 & 10.4 & 10.9 & 11.4 & 11.9 & 12.4 & 12.9 & 13.4 & 13.9 & 14.4 & 14.9 & 15.4 & 15.8 & 16.3 \\
\hline & 60 & 13.1 & 13.6 & 14.1 & 14.6 & 15.1 & 15.6 & 16.1 & 16.6 & 17.1 & 17.6 & 18.1 & 18.6 & 19.1 \\
\hline & 50 & 15.6 & 16.1 & 16.6 & 17.1 & 17.6 & 18.1 & 18.6 & 19.1 & 19.6 & 20.1 & 20.6 & 21.1 & 21.6 \\
\hline & 40 & 18.1 & 18.6 & 19.1 & 19.6 & 20.1 & 20.6 & 21.1 & 21.6 & 22.1 & 22.6 & 23.1 & 23.6 & 24.1 \\
\hline & 30 & 20.9 & 21.3 & 21.8 & 22.3 & 22.8 & 23.3 & 23.8 & 24.3 & 24.8 & 25.3 & 25.8 & 26.3 & 26.8 \\
\hline & 20 & 24.1 & 24.6 & 25.1 & 25.6 & 26.1 & 26.6 & 27.1 & 27.6 & 28.1 & 28.6 & 29.1 & 29.5 & 30.0 \\
\hline & 15 & 26.1 & 26.6 & 27.1 & 27.6 & 28.1 & 28.6 & 29.1 & 29.6 & 30.1 & 30.6 & 31.1 & 31.6 & 32.1 \\
\hline & 10 & 28.5 & 29.0 & 29.5 & 30.0 & 30.5 & 31.0 & 31.5 & 32.0 & 32.5 & 33.0 & 33.5 & 34.0 & 34.5 \\
\hline & 5 & 32.1 & 32.6 & 33.1 & 33.6 & 34.1 & 34.6 & 35.1 & 35.6 & 36.1 & 36.6 & 37.1 & 37.6 & 38.1 \\
\hline
\end{tabular}

Table A28

Normative data for the M-WCST total errors stratified by education levels for GUATEMALA

\begin{tabular}{lcc}
\hline Percentile & 1 to 12 years of education & $>12$ years of education \\
\hline 95 & - & - \\
90 & 2.1 & - \\
85 & 4.5 & - \\
80 & 6.5 & - \\
70 & 9.7 & 2.2 \\
60 & 12.4 & 4.9 \\
50 & 14.9 & 7.4 \\
40 & 17.4 & 9.8 \\
30 & 20.0 & 12.5 \\
20 & 23.2 & 15.7 \\
15 & 25.2 & 17.7 \\
10 & 27.6 & 20.1 \\
5 & 31.2 & 23.7 \\
\hline
\end{tabular}


Table A29

Normative data for the M-WCST total errors stratified by education levels for HONDURAS

\begin{tabular}{lcc}
\hline Percentile & 1 to 12 years of education & $>12$ years of education \\
\hline 95 & 1.0 & - \\
90 & 4.4 & - \\
85 & 6.7 & 1.5 \\
80 & 8.6 & 3.4 \\
70 & 11.6 & 6.4 \\
60 & 14.1 & 8.9 \\
50 & 16.5 & 11.3 \\
40 & 18.9 & 13.7 \\
30 & 21.4 & 16.2 \\
20 & 24.4 & 19.2 \\
15 & 26.3 & 21.1 \\
10 & 28.6 & 23.4 \\
5 & 32.0 & 26.8 \\
\hline
\end{tabular}

Table A30

Normative data for the M-WCST total errors stratified by age and education levels for MEXICO

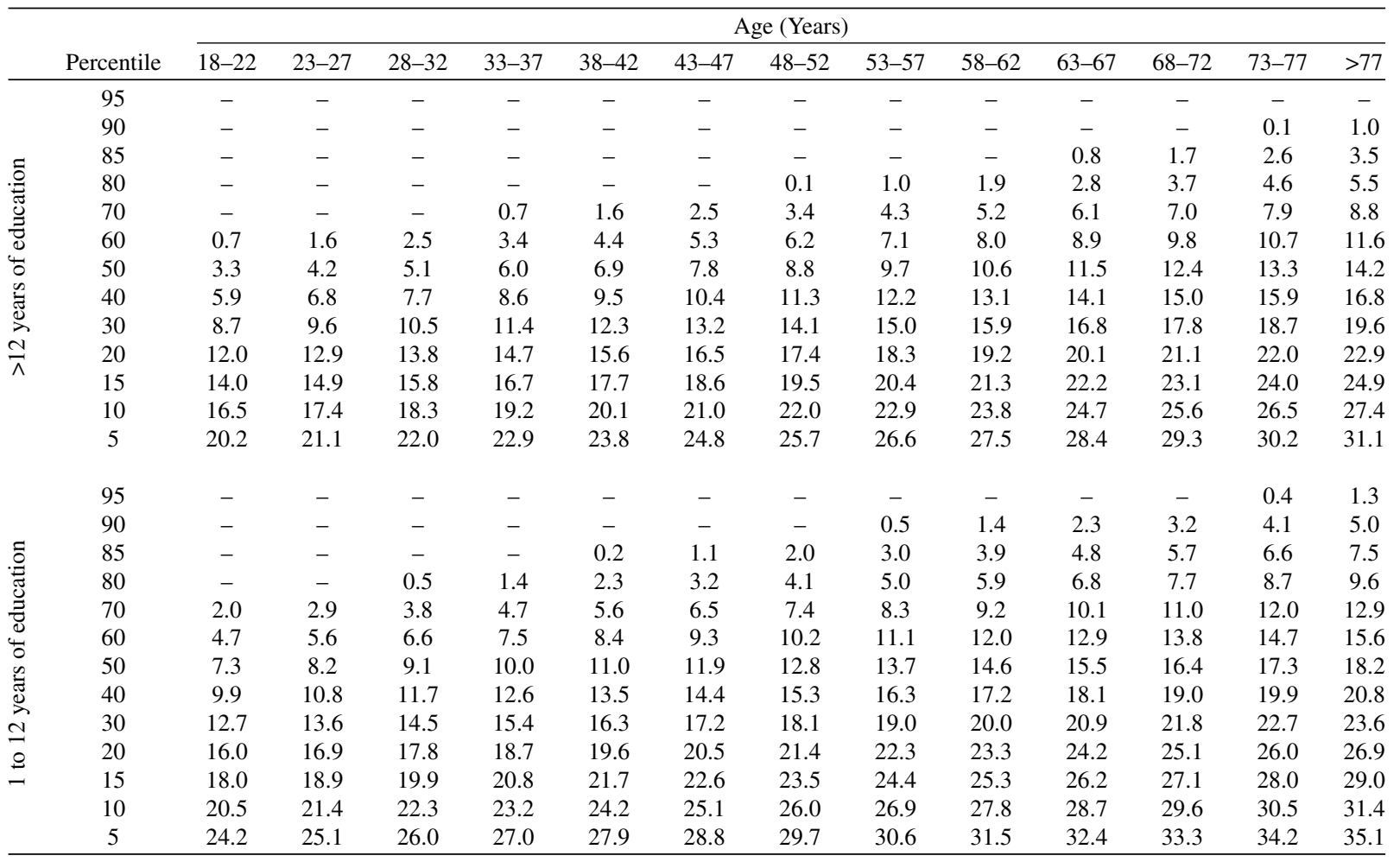


Table A31

Normative data for the M-WCST total errors stratified by age and education levels for PARAGUAY

\begin{tabular}{|c|c|c|c|c|c|c|c|c|c|c|c|c|c|c|}
\hline & \multirow[b]{2}{*}{ Percentile } & \multicolumn{13}{|c|}{ Age (Years) } \\
\hline & & $18-22$ & $23-27$ & $28-32$ & $33-37$ & $38-42$ & $43-47$ & $48-52$ & $53-57$ & $58-62$ & $63-67$ & $68-72$ & $73-77$ & $>77$ \\
\hline \multirow{13}{*}{ 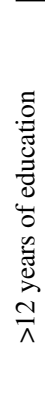 } & 95 & - & - & - & - & - & 0.2 & 1.0 & 1.9 & 2.7 & 3.6 & 4.4 & 5.2 & 6.1 \\
\hline & 90 & - & - & - & 0.3 & 1.1 & 2.0 & 2.8 & 3.6 & 4.5 & 5.3 & 6.1 & 7.0 & 7.8 \\
\hline & 85 & - & - & 0.6 & 1.5 & 2.3 & 3.1 & 4.0 & 4.8 & 5.6 & 6.5 & 7.3 & 8.1 & 9.0 \\
\hline & 80 & - & 0.8 & 1.6 & 2.4 & 3.3 & 4.1 & 4.9 & 5.8 & 6.6 & 7.4 & 8.3 & 9.1 & 10.0 \\
\hline & 70 & 1.5 & 2.3 & 3.1 & 4.0 & 4.8 & 5.7 & 6.5 & 7.3 & 8.2 & 9.0 & 9.8 & 10.7 & 11.5 \\
\hline & 60 & 2.8 & 3.6 & 4.5 & 5.3 & 6.1 & 7.0 & 7.8 & 8.6 & 9.5 & 10.3 & 11.1 & 12.0 & 12.8 \\
\hline & 50 & 4.0 & 4.8 & 5.7 & 6.5 & 7.3 & 8.2 & 9.0 & 9.9 & 10.7 & 11.5 & 12.4 & 13.2 & 14.0 \\
\hline & 40 & 5.2 & 6.0 & 6.9 & 7.7 & 8.6 & 9.4 & 10.2 & 11.1 & 11.9 & 12.7 & 13.6 & 14.4 & 15.2 \\
\hline & 30 & 6.5 & 7.4 & 8.2 & 9.0 & 9.9 & 10.7 & 11.5 & 12.4 & 13.2 & 14.0 & 14.9 & 15.7 & 16.6 \\
\hline & 20 & 8.1 & 8.9 & 9.7 & 10.6 & 11.4 & 12.3 & 13.1 & 13.9 & 14.8 & 15.6 & 16.4 & 17.3 & 18.1 \\
\hline & 15 & 9.0 & 9.9 & 10.7 & 11.6 & 12.4 & 13.2 & 14.1 & 14.9 & 15.7 & 16.6 & 17.4 & 18.2 & 19.1 \\
\hline & 10 & 10.2 & 11.0 & 11.9 & 12.7 & 13.6 & 14.4 & 15.2 & 16.1 & 16.9 & 17.7 & 18.6 & 19.4 & 20.3 \\
\hline & 5 & 12.0 & 12.8 & 13.6 & 14.5 & 15.3 & 16.1 & 17.0 & 17.8 & 18.7 & 19.5 & 20.3 & 21.2 & 22.0 \\
\hline \multirow{13}{*}{ 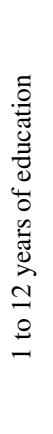 } & 95 & 0.1 & 0.9 & 1.7 & 2.6 & 3.4 & 4.2 & 5.1 & 5.9 & 6.7 & 7.6 & 8.4 & 9.3 & 10.1 \\
\hline & 90 & 1.8 & 2.6 & 3.5 & 4.3 & 5.1 & 6.0 & 6.8 & 7.7 & 8.5 & 9.3 & 10.2 & 11.0 & 11.8 \\
\hline & 85 & 3.0 & 3.8 & 4.6 & 5.5 & 6.3 & 7.2 & 8.0 & 8.8 & 9.7 & 10.5 & 11.3 & 12.2 & 13.0 \\
\hline & 80 & 3.9 & 4.8 & 5.6 & 6.4 & 7.3 & 8.1 & 9.0 & 9.8 & 10.6 & 11.5 & 12.3 & 13.1 & 14.0 \\
\hline & 70 & 5.5 & 6.3 & 7.2 & 8.0 & 8.8 & 9.7 & 10.5 & 11.3 & 12.2 & 13.0 & 13.9 & 14.7 & 15.5 \\
\hline & 60 & 6.8 & 7.6 & 8.5 & 9.3 & 10.2 & 11.0 & 11.8 & 12.7 & 13.5 & 14.3 & 15.2 & 16.0 & 16.8 \\
\hline & 50 & 8.0 & 8.9 & 9.7 & 10.5 & 11.4 & 12.2 & 13.0 & 13.9 & 14.7 & 15.5 & 16.4 & 17.2 & 18.1 \\
\hline & 40 & 9.2 & 10.1 & 10.9 & 11.7 & 12.6 & 13.4 & 14.3 & 15.1 & 15.9 & 16.8 & 17.6 & 18.4 & 19.3 \\
\hline & 30 & 10.5 & 11.4 & 12.2 & 13.1 & 13.9 & 14.7 & 15.6 & 16.4 & 17.2 & 18.1 & 18.9 & 19.7 & 20.6 \\
\hline & 20 & 12.1 & 12.9 & 13.8 & 14.6 & 15.4 & 16.3 & 17.1 & 18.0 & 18.8 & 19.6 & 20.5 & 21.3 & 22.1 \\
\hline & 15 & 13.1 & 13.9 & 14.7 & 15.6 & 16.4 & 17.3 & 18.1 & 18.9 & 19.8 & 20.6 & 21.4 & 22.3 & 23.1 \\
\hline & 10 & 14.2 & 15.1 & 15.9 & 16.7 & 17.6 & 18.4 & 19.3 & 20.1 & 20.9 & 21.8 & 22.6 & 23.4 & 24.3 \\
\hline & 5 & 16.0 & 16.8 & 17.7 & 18.5 & 19.3 & 20.2 & 21.0 & 21.8 & 22.7 & 23.5 & 24.4 & 25.2 & 26.0 \\
\hline
\end{tabular}

Table A32

Normative data for the M-WCST total errors stratified by age and education levels for PERU

\begin{tabular}{|c|c|c|c|c|c|c|c|c|c|c|c|c|c|c|}
\hline & \multirow[b]{2}{*}{ Percentile } & \multicolumn{13}{|c|}{ Age (Years) } \\
\hline & & $18-22$ & $23-27$ & $28-32$ & $33-37$ & $38-42$ & $43-47$ & $48-52$ & $53-57$ & $58-62$ & $63-67$ & $68-72$ & $73-77$ & $>77$ \\
\hline \multirow{13}{*}{ 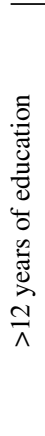 } & 95 & - & - & - & - & - & - & - & - & - & 1.0 & 1.9 & 2.9 & 3.9 \\
\hline & 90 & - & - & - & - & - & 0.1 & 1.0 & 2.0 & 3.0 & 4.0 & 4.9 & 5.9 & 6.9 \\
\hline & 85 & - & - & - & 0.1 & 1.1 & 2.0 & 3.0 & 4.0 & 5.0 & 5.9 & 6.9 & 7.9 & 8.9 \\
\hline & 80 & - & - & 0.8 & 1.7 & 2.7 & 3.7 & 4.7 & 5.6 & 6.6 & 7.6 & 8.6 & 9.5 & 10.5 \\
\hline & 70 & 1.5 & 2.4 & 3.4 & 4.4 & 5.4 & 6.3 & 7.3 & 8.3 & 9.3 & 10.2 & 11.2 & 12.2 & 13.2 \\
\hline & 60 & 3.7 & 4.7 & 5.6 & 6.6 & 7.6 & 8.6 & 9.5 & 10.5 & 11.5 & 12.5 & 13.4 & 14.4 & 15.4 \\
\hline & 50 & 5.8 & 6.7 & 7.7 & 8.7 & 9.7 & 10.6 & 11.6 & 12.6 & 13.6 & 14.5 & 15.5 & 16.5 & 17.5 \\
\hline & 40 & 7.8 & 8.8 & 9.8 & 10.8 & 11.7 & 12.7 & 13.7 & 14.7 & 15.6 & 16.6 & 17.6 & 18.6 & 19.5 \\
\hline & 30 & 10.1 & 11.0 & 12.0 & 13.0 & 14.0 & 14.9 & 15.9 & 16.9 & 17.9 & 18.8 & 19.8 & 20.8 & 21.8 \\
\hline & 20 & 12.7 & 13.7 & 14.7 & 15.6 & 16.6 & 17.6 & 18.6 & 19.5 & 20.5 & 21.5 & 22.5 & 23.4 & 24.4 \\
\hline & 15 & 14.4 & 15.3 & 16.3 & 17.3 & 18.3 & 19.2 & 20.2 & 21.2 & 22.2 & 23.1 & 24.1 & 25.1 & 26.1 \\
\hline & 10 & 16.4 & 17.3 & 18.3 & 19.3 & 20.3 & 21.2 & 22.2 & 23.2 & 24.2 & 25.1 & 26.1 & 27.1 & 28.0 \\
\hline & 5 & 19.3 & 20.3 & 21.3 & 22.3 & 23.2 & 24.2 & 25.2 & 26.2 & 27.1 & 28.1 & 29.1 & 30.1 & 31.0 \\
\hline \multirow{13}{*}{ 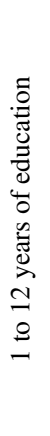 } & 95 & - & - & - & - & 0.6 & 1.6 & 2.5 & 3.5 & 4.5 & 5.5 & 6.4 & 7.4 & 8.4 \\
\hline & 90 & - & 0.6 & 1.6 & 2.6 & 3.6 & 4.5 & 5.5 & 6.5 & 7.5 & 8.4 & 9.4 & 10.4 & 11.4 \\
\hline & 85 & 1.7 & 2.6 & 3.6 & 4.6 & 5.6 & 6.5 & 7.5 & 8.5 & 9.5 & 10.4 & 11.4 & 12.4 & 13.4 \\
\hline & 80 & 3.3 & 4.3 & 5.3 & 6.2 & 7.2 & 8.2 & 9.2 & 10.1 & 11.1 & 12.1 & 13.1 & 14.0 & 15.0 \\
\hline & 70 & 6.0 & 6.9 & 7.9 & 8.9 & 9.9 & 10.8 & 11.8 & 12.8 & 13.8 & 14.7 & 15.7 & 16.7 & 17.7 \\
\hline & 60 & 8.2 & 9.2 & 10.1 & 11.1 & 12.1 & 13.1 & 14.0 & 15.0 & 16.0 & 17.0 & 17.9 & 18.9 & 19.9 \\
\hline & 50 & 10.3 & 11.2 & 12.2 & 13.2 & 14.2 & 15.1 & 16.1 & 17.1 & 18.1 & 19.0 & 20.0 & 21.0 & 22.0 \\
\hline & 40 & 12.3 & 13.3 & 14.3 & 15.3 & 16.2 & 17.2 & 18.2 & 19.2 & 20.1 & 21.1 & 22.1 & 23.1 & 24.0 \\
\hline & 30 & 14.6 & 15.5 & 16.5 & 17.5 & 18.5 & 19.4 & 20.4 & 21.4 & 22.4 & 23.3 & 24.3 & 25.3 & 26.3 \\
\hline & 20 & 17.2 & 18.2 & 19.2 & 20.1 & 21.1 & 22.1 & 23.1 & 24.0 & 25.0 & 26.0 & 27.0 & 27.9 & 28.9 \\
\hline & 15 & 18.9 & 19.8 & 20.8 & 21.8 & 22.8 & 23.7 & 24.7 & 25.7 & 26.7 & 27.6 & 28.6 & 29.6 & 30.6 \\
\hline & 10 & 20.8 & 21.8 & 22.8 & 23.8 & 24.7 & 25.7 & 26.7 & 27.7 & 28.6 & 29.6 & 30.6 & 31.6 & 32.5 \\
\hline & 5 & 23.8 & 24.8 & 25.8 & 26.8 & 27.7 & 28.7 & 29.7 & 30.6 & 31.6 & 32.6 & 33.6 & 34.5 & 35.5 \\
\hline
\end{tabular}


Table A33

Normative data for the M-WCST total errors stratified by age and education levels for PUERTO RICO

\begin{tabular}{|c|c|c|c|c|c|c|c|c|c|c|c|c|c|c|}
\hline & \multirow[b]{2}{*}{ Percentile } & \multicolumn{13}{|c|}{ Age (Years) } \\
\hline & & $18-22$ & $23-27$ & $28-32$ & $33-37$ & $38-42$ & $43-47$ & $48-52$ & $53-57$ & $58-62$ & $63-67$ & $68-72$ & $73-77$ & $>77$ \\
\hline \multirow{13}{*}{ 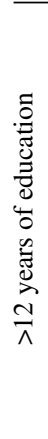 } & 95 & - & - & - & - & - & - & - & - & - & - & - & - & - \\
\hline & 90 & - & - & - & - & - & - & - & - & - & - & - & 0.8 & 1.7 \\
\hline & 85 & - & - & - & - & - & - & - & - & 0.2 & 1.1 & 2.0 & 3.0 & 3.9 \\
\hline & 80 & - & - & - & - & - & - & 0.1 & 1.0 & 2.0 & 2.9 & 3.9 & 4.8 & 5.8 \\
\hline & 70 & - & - & - & 0.2 & 1.1 & 2.1 & 3.0 & 4.0 & 4.9 & 5.9 & 6.8 & 7.7 & 8.7 \\
\hline & 60 & - & 0.8 & 1.7 & 2.7 & 3.6 & 4.5 & 5.5 & 6.4 & 7.4 & 8.3 & 9.3 & 10.2 & 11.1 \\
\hline & 50 & 2.1 & 3.1 & 4.0 & 4.9 & 5.9 & 6.8 & 7.8 & 8.7 & 9.7 & 10.6 & 11.5 & 12.5 & 13.4 \\
\hline & 40 & 4.4 & 5.3 & 6.3 & 7.2 & 8.2 & 9.1 & 10.1 & 11.0 & 11.9 & 12.9 & 13.8 & 14.8 & 15.7 \\
\hline & 30 & 6.9 & 7.8 & 8.8 & 9.7 & 10.6 & 11.6 & 12.5 & 13.5 & 14.4 & 15.4 & 16.3 & 17.2 & 18.2 \\
\hline & 20 & 9.8 & 10.7 & 11.7 & 12.6 & 13.6 & 14.5 & 15.5 & 16.4 & 17.3 & 18.3 & 19.2 & 20.2 & 21.1 \\
\hline & 15 & 11.6 & 12.6 & 13.5 & 14.5 & 15.4 & 16.3 & 17.3 & 18.2 & 19.2 & 20.1 & 21.1 & 22.0 & 22.9 \\
\hline & 10 & 13.8 & 14.8 & 15.7 & 16.6 & 17.6 & 18.5 & 19.5 & 20.4 & 21.4 & 22.3 & 23.3 & 24.2 & 25.1 \\
\hline & 5 & 17.1 & 18.1 & 19.0 & 19.9 & 20.9 & 21.8 & 22.8 & 23.7 & 24.7 & 25.6 & 26.5 & 27.5 & 28.4 \\
\hline \multirow{13}{*}{ 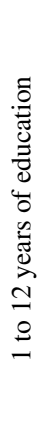 } & 95 & - & - & - & - & - & - & - & - & - & - & - & 0.4 & 1.4 \\
\hline & 90 & - & - & - & - & - & - & - & - & 0.9 & 1.8 & 2.8 & 3.7 & 4.7 \\
\hline & 85 & - & - & - & - & - & 0.3 & 1.2 & 2.1 & 3.1 & 4.0 & 5.0 & 5.9 & 6.9 \\
\hline & 80 & - & - & - & 0.2 & 1.1 & 2.1 & 3.0 & 4.0 & 4.9 & 5.9 & 6.8 & 7.8 & 8.7 \\
\hline & 70 & 0.3 & 1.2 & 2.2 & 3.1 & 4.1 & 5.0 & 6.0 & 6.9 & 7.8 & 8.8 & 9.7 & 10.7 & 11.6 \\
\hline & 60 & 2.8 & 3.7 & 4.7 & 5.6 & 6.5 & 7.5 & 8.4 & 9.4 & 10.3 & 11.3 & 12.2 & 13.1 & 14.1 \\
\hline & 50 & 5.1 & 6.0 & 6.9 & 7.9 & 8.8 & 9.8 & 10.7 & 11.7 & 12.6 & 13.5 & 14.5 & 15.4 & 16.4 \\
\hline & 40 & 7.3 & 8.3 & 9.2 & 10.2 & 11.1 & 12.1 & 13.0 & 13.9 & 14.9 & 15.8 & 16.8 & 17.7 & 18.7 \\
\hline & 30 & 9.8 & 10.8 & 11.7 & 12.6 & 13.6 & 14.5 & 15.5 & 16.4 & 17.4 & 18.3 & 19.2 & 20.2 & 21.1 \\
\hline & 20 & 12.7 & 13.7 & 14.6 & 15.6 & 16.5 & 17.5 & 18.4 & 19.3 & 20.3 & 21.2 & 22.2 & 23.1 & 24.1 \\
\hline & 15 & 14.6 & 15.5 & 16.5 & 17.4 & 18.3 & 19.3 & 20.2 & 21.2 & 22.1 & 23.1 & 24.0 & 24.9 & 25.9 \\
\hline & 10 & 16.8 & 17.7 & 18.6 & 19.6 & 20.5 & 21.5 & 22.4 & 23.4 & 24.3 & 25.2 & 26.2 & 27.1 & 28.1 \\
\hline & 5 & 20.1 & 21.0 & 21.9 & 22.9 & 23.8 & 24.8 & 25.7 & 26.7 & 27.6 & 28.5 & 29.5 & 30.4 & 31.4 \\
\hline
\end{tabular}

